
\title{
3 Research Square \\ Spatiotemporal evolution and assembly processes of ammonia-oxidising prokaryotic communities in coastal reclaimed soils
}

\section{Sarfraz Hussain}

Nanjing Agricultural University College of Life Sciences

\section{Yifan Yin}

Nanjing Agricultural University College of Life Sciences

Senlin Liu

Nanjing Agricultural University College of Life Sciences

Shanshan Yan

Nanjing Agricultural University College of Life Sciences

\section{Dongjie Chen}

Nanjing Agricultural University College of Life Sciences

\section{Feng Wang}

Institute of Eco-Environmental Sciences, Ningbo institute of Agricultural Sciences, Ningbo,China

Cao Hui ( $\nabla$ hcao@njau.edu.cn )

Nanjing Agricultural University College of Life Sciences https://orcid.org/0000-0003-3406-3803

\section{Research}

Keywords: Coastal Salt Marshes, Deterministic, Stochastic, $\beta N T I$, Community Assembly, Ammonia Oxidiser

Posted Date: May 5th, 2021

DOI: https://doi.org/10.21203/rs.3.rs-424992/v1

License: (c) (i) This work is licensed under a Creative Commons Attribution 4.0 International License. Read Full License 


\section{Abstract}

\section{Background}

In microbial ecology, the processes underlying functional community assembly and spatiotemporal effect are often ignored. The effects of land management and reclamation of coastal marshes on microbial communities have been studied with great interest; however, most of these studies have described shortterm changes in soil microbial community dynamics. Therefore, ammonia-oxidising prokaryotic communities that play an essential role in nitrogen cycling have not been studied in long-term reclamations of coastal marshes. Here, we investigated archaeal and bacterial ammonia-oxidising prokaryotic communities in coastal salt marsh soils that were reclaimed over 1000 years, evaluating the abundance, composition, taxonomic and phylogenetic diversity by using qPCR and lonS $5^{\mathrm{TM}} \mathrm{XL}$ sequencing platforms. We analysed phylogenetic diversity and assemblages of ammonia oxidisers using the Nearest Related Index , Nearest Taxon Index , beta Mean Nearest Taxon Distance and beta Nearest Taxon Index .

\section{Results}

The taxonomic \& phylogenetic alpha diversity and composition of the ammonia-oxidizers showed apparent spatiotemporal variations along reclamation of soil. Phylogenetic beta diversity indices, Weighted UniFrac dissimilarity and beta Mean Nearest Taxon Distance of both communities were positively correlated with geographical distance and environmental variables. Across all sites, the archaeal ammonia-oxidising community assembled by a deterministic process $(84.71 \%)$. The bacterial ammonia-oxidising community was formed more by a stochastic process in coastal marshes and at reclamation stage 60 years $(|\beta N T| \mid<2)$, despite its relatively dominant deterministic process $(55.2 \%)$. Archaeal $a m o A$ gene abundance increased significantly among reclamation stages and was positively correlated with the nitrification rate.

\section{Conclusion}

Our study revealed that during the 1000 years of reclamation coastal wetlands (1) a clear spatiotemporal evolution of the $a m o A$ gene harboured prokaryotic communities; (2) the soil properties and $\mathrm{N}$ cycling were significantly affected; and (3) the significant impact on ammonia oxidisers assemblages' dynamics. These findings provide a better understanding of how long-term land management affect soil $\mathrm{N}$ cycling and ammonia-oxidising communities including assembly dynamics, abundance and community distribution. Further researches are needed to study the effect of soil disruption and community assembly processes on soil nitrogen cycling, such as nitrogen fixation and denitrification, in order to exploit the functional microbial population in predictable ways, improve crop yields and soil sustainability.

\section{Background}


The microbial community composition is associated with the surrounding environment, and consequently environmental conditions can alter the microbial community structure [1]. In recent decades, increasing human activity and unusual frequent natural events have an intense effect on microbial community dynamics, and it would also affect biogeochemical cycling and ecosystem functioning [2]. Several anthropogenic and natural activities are responsible for controlling the association between environmental and microbial dynamics, which ultimately contributes to microbiota assembly. Both stochastic and deterministic processes control microbial biogeography and differ in their relative contribution to microbiota assembly over different tempo-spatial scales [3]. However, spatial scales can be a deterministic factor when correlated with functional traits (niche), population size, and environmental factors, affecting the dispersion of different taxa [4]. The ancient theory of a niche shows that biodiversity regulation is based on biotic (inter taxa interaction) and abiotic (environmental heterogeneity) factors. In contrast, microbe-microbe interactions are less understood than microbeenvironment interactions [5]. A central theme in ecology is the interpretation of variables that regulate spatiotemporal differences in the composition of microbial communities, along with environmental factors $[6,7]$.

Salt marshes are the most productive and valuable habitats and play a crucial role in the protection of coastal regions, while being vulnerable to climate change and anthropogenic destruction [8-10]. Reclamation of coastal wetlands has turned out to be a popular activity around the world to provide more space for anthropogenic activities. Therefore, wide areas of coastal marshes are now being used for agriculture, transportation infrastructure, and industry. However, this large-scale reclamation activity has caused unprecedented damage and interference to coastal marshlands. Reclamation creates significant environmental threats, therefore becoming a global issue. Nitrification and denitrification of nitrogen in salt marshes has been incorporated by either plant biomass or the local microbiota [11]. The primary and rate-limiting stage of nitrification is known to be ammonia oxidation driven by ammonia-oxidising archaea (AOA) and bacteria (AOB), which play a significant role in maintaining the nitrogen cycle [12, 13]. Recent studies have investigated spatiotemporal variations in microbial communities, but debate exists over the drivers and how microbially driven mechanisms are ultimately affected [14-16]. Numerous studies have indicated that the trajectories, such as the disentangled relationship between ecological mechanisms and edaphic factors exhibited by microbial communities are helpful to structure microbial populations in disturbed and natural soil $[17,18]$.

Limited studies have investigated the successional pattern of microbial communities based on agricultural land, post-mining regions, and glacial foreland over chronosequence [19-21]. A chronosequence of soil formation may depend on spatiotemporal fluctuations in ammonia oxidiser populations and the dynamics of ecosystem development over a time scale [22]. In recent years, extensive work in molecular biology has aided the investigation of $A O A$ and $A O B$ ecology via amoA gene surveys. In this study, we analysed community assemblages of ammonia oxidisers using effective statistical methods, including the Mean Pairwise Distance standardised-effect size (ses.MPD), Nearest Related Index (NRI), Mean Nearest Taxon Distance standardised-effect size (ses.MNTD), Nearest Taxon Index (NTI), beta Mean Nearest Taxon Distance (BMNTD), and beta Nearest Taxon Index ( $\beta N T I)$. In turn, 
using the approach described above, we sought to quantify the possible $A O A$ and $A O B$ in ecosystem functioning along chronosequence of soil formation. We hypothesised that (1) along with the chronosequence of reclaimed soils, $\mathrm{AOA}$ and $\mathrm{AOB}$ community composition and structure varied distinctly due to the strong influences of soil physicochemical properties and geographic distance, (2) ecosystem function provides quantitative information about microbial communities' response to environmental conditions, and (3) with the change of environment and land management, there is a specific corresponding relationship between ammonia-oxidising prokaryotic communities and ecosystem function.

\section{Materials And Methods}

\section{Study area description and field soil sampling}

The present study was conducted on the south coast of Hangzhou Bay $\left(121^{\circ} 05^{\prime}-121^{\circ} 35^{\prime \prime} \mathrm{E}, 30^{\circ} 0^{\prime}-30^{\circ} 25^{\prime} \mathrm{N}\right)$ in Cixi County, Zhejiang Province, China. The study area is a typical northern subtropical monsoon climate zone, with a mean annual precipitation of $1273 \mathrm{~mm}$ and temperature of $16.0^{\circ} \mathrm{C}$. Salt marshes formed from the Qiantang Estuary saltwater sediments and diked lands were exposed to tidal effects at an elevation range from 2.6 to $5.7 \mathrm{~m} \mathrm{[23].} \mathrm{The} \mathrm{tidal} \mathrm{salty} \mathrm{marsh} \mathrm{was} \mathrm{eventually} \mathrm{reclaimed} \mathrm{for} \mathrm{crop} \mathrm{growth,}$ beginning 1000 years ago with the formation of dikes at different historical stages. Based on the construction times of dikes, the years of soil reclamation were calculated, and a detailed description is available online in Chinese at (www.cixi.gov.cn). In this study, around 1000 years of ancient spanning of soil chronosequence was identified, including undisturbed coastal salty marsh (T0) and soil reclaimed 5years (T5), 20-years (T20), 50-years (T50), 60-years (T60), 120-years (T120), 200-years (T200), 220-years (T220), 280-years (T280), 500-years (T500), and 1000-years (T1000) ago.

Distances between these soils were no more han $30 \mathrm{~km}$ in a similar topography. Soil samples were collected and mixed from six random locations, and then six mixed soils sampled from the same reclaimed year were considered replicates. A stainless-steel auger (3-cm diameter) was used for soil collection. Briefly, soil samples were taken from the plough layer $(0-20 \mathrm{~cm})$, and a total of 66 samples were obtained representing specific reclamation years (Fig. S1). The taxonomic class of soil samples was fluvisol as per Food and Agriculture Organization/United Nations Educational, Scientific and Cultural Organization (FAO/UNESCO), which was formed from fluvial deposits around the Qiantang River, and the soil texture was silty loam to clay-loam [24, 25]. In December 2015, reclamation site samples (T5-T1000) were collected from a traditional soybean-broccoli rotation field during active broccoli growth from crop free sites to avoid the possible impact of plant roots. Compound fertilisers were applied @ $900 \mathrm{~kg} \cdot \mathrm{ha}^{-1}$, of which nitrogen $(\mathrm{N})$ :phosphorus $\left(\mathrm{P}_{2} \mathrm{O}_{5}\right)$ :potassium $\left(\mathrm{K}_{2} \mathrm{O}\right)$ was estimated to be 1:1:1. The salt marsh soils (T0) were sampled in the high-tide area under Phragmites australis. Samples were immediately taken to the laboratory on ice packs and then sieved through a $2 \mathrm{~mm}$ mesh to remove roots and another residue. After that, sieved soils were divided into three parts; two parts were kept at $-80^{\circ} \mathrm{C}$ and $4^{\circ} \mathrm{C}$ for total DNA extraction, mineralised $\mathrm{N}$ content, and nitrification analysis. The third part was air-dried for the determination of physicochemical parameters of the soil. 


\section{Total DNA extraction}

The soil total genomic DNA was extracted using the Soil DNA kit (Omega Bio-Tek, Inc., Norcross, GA, USA) according to the manufacturer's instructions from $0.5 \mathrm{~g}$ of soil. The purity and quality of DNA were measured by $1 \%$ agarose gel electrophoresis and a spectrophotometer, respectively (Nanodrop, PeqLab, Germany).

\section{Amplification and sequencing of the amoA gene for $\mathrm{AOA}$ and $\mathrm{AOB}$}

The amoA gene of archaea and bacteria was amplified by polymerase chain reaction (PCR) using ArchamoAF (5'- STAATGGTCTGGCTTAGACG-3'), Arch-amoAR (5'-GCGGCCA TCCATCTGTATGT-3') and amoA1F (5'-GGGGTTTCTACTGGTGGT -3') and amoA-2R (5'- CCCCTCKGSAAAGCCTTCTTC -3') respectively. PCR was performed with $15 \mu \mathrm{L}$ of Phusion $\AA$ High-Fidelity PCR Master Mix (New England Biolabs), 0.2 $\mu \mathrm{M} / \mu \mathrm{L}$ forward and reverse primers, and $10 \mathrm{ng} / \mu \mathrm{L}$ DNA template. The following cycling parameter were used: incubation at $95^{\circ} \mathrm{C}$ for $5 \mathrm{~min}$, followed by 30 cycles of $95^{\circ} \mathrm{C}$ for $30 \mathrm{~s}, 56^{\circ} \mathrm{C}$ and $58^{\circ} \mathrm{C}$ for $60 \mathrm{~s}, 72^{\circ} \mathrm{C}$ for $60 \mathrm{~s}$ and $35 \mathrm{~s} \mathrm{(archaea} \mathrm{and} \mathrm{bacteria,} \mathrm{respectively),} \mathrm{and} \mathrm{a} \mathrm{final} 10$ min extension at $72^{\circ} \mathrm{C}$. The PCR product was recovered and purified by $2 \%$ agarose gel electrophoresis and GeneJET Gel Extraction kit (Thermo Fisher Scientific USA). According to the manufacturer's instructions, sequencing libraries were constructed using the lon Plus Fragment Library Kit 48 rxns (Thermo Scientific). The library quality was estimated with a Qubit@ 2.0 Fluorometer (Thermo Scientific), and the library was sequenced on an Ion S5TM XL platform.

\section{Quantification of the amoA gene in $A O A$ and $A O B$}

To estimate the amoA functional gene for $A O A$ and $A O B$, quantitative PCR (qPCR) was performed. The ammonia-oxidising archaeal $a m o A$ gene was quantified by fluorescence qPCR using the primers shown above (section 2.3). Absolute quantification was carried out on the Applied Biosystems QuantStudio ${ }^{\mathrm{TM}} 6$ Flex Real-Time PCR System (Life Technologies Corporation, Carls-bad, CA, USA) amplifier using Hieff ${ }^{\circledR}$ qPCR SYBE ${ }^{\circledR}$ Green Master Mix (YEASEN). The fluorescence qPCR reaction volume was $20 \mu$ l, containing $10 \mu \mathrm{l} 2 \times$ SYBR Green Mix, $0.8 \mu \mathrm{l}$ upstream and downstream primers $(10 \mathrm{pmol} / \mu \mathrm{l}), 1 \mu \mathrm{l}$ diluted total DNA template, and $7.4 \mu \mathrm{l}$ double distilled water. The protocol for the PCR reaction was as follows: predenaturation at $95^{\circ} \mathrm{C}$ for $5 \mathrm{~min} ; 40$ cycles at $95^{\circ} \mathrm{C}$ for $30 \mathrm{~s}$, annealing at $56^{\circ} \mathrm{C}$ and $58^{\circ} \mathrm{C}$ for $60 \mathrm{~s}$, and extension at $72^{\circ} \mathrm{C}$ for $60 \mathrm{~s}$ and $35 \mathrm{~s}$ (archaea and bacteria, respectively); the melting curve temperature range was $65-95^{\circ} \mathrm{C}$.

\section{Sequencing data processing and analysis}

Single-end reads were assigned to samples based on their unique barcode, and Cutadapt (V1.9.1) was used for quality filtering to obtain high-quality clean reads [26]. Reads were analysed by the Silva database using the UCHIME algorithm to classify and delete chimera sequences [27, 28]. The Uparse program grouped the purified sequences (Uparse v7.0.1001). The same operational taxonomic units (OTUs) were assigned sequences with $97 \%$ identity [29]. The Mothur algorithm [30] was used to perform 
annotated OTU analysis to obtain representative species and count the number of OTUs per sample in taxonomic information (Kingdom, Phylum, Class, Order, Family, Genus, and Species level). Archaeal and bacterial OTUs were identified and assigned in the archaeal and bacterial Silva Database [27]. For multiple sequence alignment, MUSCLE software (Version 3.8.31) was used to examine the phylogenetic relationship between different OTUs and the classification of the dominant species in different samples [31].

\section{Phylogenetic diversity matrices analysis}

The Mean Phylogenetic Distance (MPD) determined by Net Relatedness Index (NRI) for all co-occurring populations revealed 'basal dispersal' within the population, while the Net Taxon Index (NTI) measures the Mean Nearest Taxon Distance (MNTD) between populations, thus calculating the population 'terminal' phylogenetic dispersion [32]. The MPD and MNTD standardised effect size was measured using the ses.MPD and ses.MNTD commands in the 'Picante' package of R [33]. The distribution of 999 null values, computed by shuffling the tip labels in the tree, was used to account for temporal changes of the species pool. ses.MPD. observed ses.MNTD. The observed values were multiplied by -1 to be equivalent to the NRI and NTI [33].

NRI= -(MPDobserved-MPDrandomised)/(sdMPDrandomised) [32]

NTI = -(MNTDObserved - MNTDRandomised) / (sdMNTDRandomised) [33]

The beta Means Nearest Taxon Distance (BMNTD) was computed as previously described [34]. The beta Nearest Taxon Index ( $\beta N T I)$ and standard deviation of $\beta$ MNTD were calculated in $R$ with the package MicEco by using command ses.comdistnt (abundance.weighted= True) [35]. The significance was calculated using 9999 permutations with the 'ade4' package in R. Overall environmental and geographical differences were calculated as standardised Euclidean distances between samples.

\section{Statistical analyses}

Microbial diversity and a comparison of gene copy numbers were evaluated by one-way analysis of variance (ANOVA), followed by Duncan's multiple range test at SPSS 25.0 for Windows. Discrepancies were considered statistically significant at $\mathrm{P}<0.05$. Soil ecosystem function (potential nitrification and nitrogen mineralisation rates) correlation with environmental parameters and $a m o A$ gene abundance, as well as reclaimed soil age, were calculated by Spearman's correlation analysis. Alpha diversity analysis namely observed-species, Chao1, Shannon, Simpson, ACE, and good-coverage, were calculated with QIIME (Version1.7.0). Beta diversity analysis was performed on QIIME software (Version1.7.0) to evaluate the differences in community complexity among samples and to calculate the Unique Fraction (UniFrac) distance. The Unweighted pair group method with arithmetic mean (UPGMA) sample clustering was conducted in R software (Version 2.15.3). NMDS (non-metric multi-dimensional scaling) analysis and non-parametric Analysis of Similarity (ANOSIM) based on the Bray-Curtis distance for analysing compositional differences between ammonia oxidiser prokaryotic communities were performed in $\mathrm{R}$ 
software (Version 2.15.3). Differential abundance of ammonia oxidiser between individual samples was calculated by MetaStat analysis [36].

Temporal variations in phylogenetic beta diversity were analysed by Permutational Multivariate Analysis of Variation (PERMANOVA) using $R$ function ADONIS based on the Bray-Curtis distance. The effect of physical and chemical factors on ammonia-oxidising microbial communities was analysed by canonical correspondence analysis (CCA). The cca-envfit function was used to test the impact of each environmental factor on the distribution of species. Spearman rank correlation coefficient analysis was used to correlate the relationship of environmental factors and reclaimed soil stages with ammonia oxidiser microbial abundance (alpha diversity) and species distribution. We conducted correlation analyses to assess the relationship of environmental variables with NTI and NRI to examine the change in community structure by Spearman's correlation. The mechanisms of ammonia oxidiser community assembly were determined by calculating $\beta N T I$. Briefly, if $\beta N T I>2$ or $\beta N T I<-2$, deterministic processes may be important in shaping the community composition across all sites, whereas stochastic processes may play a significant role in community assembly processes when the values of $\beta N T I$ are between -2 and 2 . The $\beta \mathrm{NTI}>2$ revealed significantly more phylogenetic turnover than predicted, which is often interpreted by chance as variable selections, while $\beta \mathrm{NTI}<2$ referred to less phylogenetic turnover than expected, i.e., homogeneous selection (Stegen et al. 2013). If the measured $\beta M N T D$ values did not bring clarity to significant differences from the null distribution of $\beta M N T D$, e.g. $|\beta N T I|<2$, the observed phylogenetic variability was not the consequence of selection [37]. To overcome this problem, the BrayCurtis-based Raup-Crick metric $\left(\mathrm{RC}_{\text {bray }}\right)$ was further determined as described by [38]. Briefly, the values of $\left(\mathrm{RC}_{\text {bray }}\right)$ ranged between -1 and 1 , and we compared $|\beta N T I|<2$ and $\left(\mathrm{RC}_{\text {bray }}\right)$ values. The relative contribution of dispersal limitation was estimated as the percentage of pairwise comparison between I $\beta N T \|<2$ and $\left(R_{\text {bray }}\right)$ values $>0.95$, whereas $|\beta N T I|<2$ and $\left(R C_{\text {bray }}\right)$ values $>-0.95$ indicated homogenous dispersal. The undominated process was calculated as $|\beta N T| \mid<2$ and $\left(R C_{\text {bray }}\right)$ values $>$ 0.95. The undominated concept described a state wherein the primary cause of variations between population compositions was neither dispersion nor selection, namely ecological drift (population sizes fluctuating due to stochastic birth and death events) [39]. We applied ordinary least-squares regression analysis to determine the slope of the association among phylogenetic relatedness with environmental factors. The Mantel tests assessed the association of phylogenetic distance and environmental parameters with geographic distance. Using partial Mantel tests with Pearson's correlation coefficient and 999 permutations, the relationships between $\beta N T I$, geographical distance, and Euclidean distances in environmental parameters were analysed.

\section{Results}

\section{$\mathrm{AOA}$ and $\mathrm{AOB}$ community composition}

A total of 840 and 714 archaeal and bacterial OTUs, respectively, were obtained, and community' annotations were performed on the OTU sequences by comparison to the Silva132 database. The archaeal community shared OTUs (14.4\%) in all soil samples (Fig. 1A), and coastal salt marsh soil 
exhibited the highest number of unique OTUs (55.8\%) compared with reclaimed soils. The archaeal community had 457 annotated OTUs (54.40\%). The overall proportion of annotated OTUs at the phylum level was $24.17 \%$. The cumulative archaeal community composition is shown in Fig. 1B. The relative abundance of AOA phylum Crenarchaeota in coastal salt marsh soil was $19.1 \%$, and it increased to $48.9 \%$ after five years of reclamation and then decreased (from 12.3 to $6.6 \%$ in the soil 20 and 50 years after reclamation, respectively), showing an asymmetrical distribution along with chronosequence. A linear increase in relative abundance was found with reclamation time ranging from 60 to 280 years (from 39.1 to $56.6 \%$, respectively) and reached the highest abundance in soil reclaimed 500 years ago $(63.2 \%)$. Abundance decreased in the 1000-year-old reclaimed soil (10.3\%). The relative abundance of the phylum Thaumarchaeota decreased linearly with reclaimed years, with $27.0 \%$ in the marsh soil and $0.1 \%$ in the 1000 -year reclaimed soil. The community distribution of AOA in the 1000-year reclaimed soil was relatively low as determined by meta stat analysis, and there were significant differences in archaeal community composition among the soils with different reclamation years (Fig. S2). The proportion of OTUs shared by ammonia-oxidising bacteria in the soil during different reclamation years was $16 \%$, with the lowest unique OTUs in T500 (0.5\%) and the highest in T0 (17\%) (Fig. 1C). The abundance of Proteobacteria, the most predominant bacterial phylum across all soil samples (19.1\%), was detected, and it was the highest $(61 \%)$ in the salt marsh and decreased with the number of reclaimed years (from $42 \%$ in 5-year reclaimed soil to $3 \%$ in 1000-year reclaimed soil). The relative abundance of Nitrosospira and Nitrosomonas was 5 and 3\%, respectively, in 5-year reclaimed soil and decreased at later reclamation stages (Fig. 1D). Metastat analysis (Fig. S3) further proved that the abundance of proteobacteria community composition significantly decreased from the coastal salt marsh to 1000-year-old reclaimed soil, while a contradictory trend was noted in the composition of uncultured bacteria. The community composition of others (uncultured bacteria and uncultured prokaryotes) significantly decreased in 5- to 20-year-old reclaimed soil.

\section{amoA gene copy number and its association with nitrification rate}

To quantify the number of amoA gene copies in archaeal and bacterial communities across all reclaimed soils, quantitative PCR was used (Fig. 2A). Reactions were performed in triplicate for all soils, with an efficiency of $92 \%$ and $96 \%$ for archaeal and bacterial amoA genes, respectively $\left(r^{2}=0.99\right)$. Archaeal amoA gene abundance increased progressively with reclaimed time (from marsh to 1000-year reclaimed soil). Bacterial amoA gene abundance showed a similar trend along reclamation time. In the reclaimed soils, both archaeal and bacterial aomA gene abundance was greater than that in the marsh and youngest reclaimed soil. In addition, Pearson's correlation analysis showed that the abundance of the archaeal amoA gene was negatively correlated with $\mathrm{pH}$, electron conductivity (EC), and available potassium (AK) and positively correlated with soil organic matter (SOM), available nitrogen (AN), total nitrogen (TN), and reclamation years (Table S1). Bacterial aomA gene abundance was positively associated with AP and negatively associated with EC. The nitrification rate was significantly and positively correlated with archaeal aomA gene abundance $(P<0.01)$, while the net nitrogen mineralisation 
rate was not significant. Furthermore, bacterial amoA gene abundance was not associated with nitrification rate and net nitrogen mineralisation.

\section{Taxonomic and phylogenetic alpha diversity analysis}

Faith's phylogenetic diversity (PD) values of ammonia oxidiser communities generally decreased along with soil chronosequence. To determine whether the $A O A$ and $A O B$ community structure assembled via stochastic or deterministic processes among reclaimed soil, the NRI and NTI were calculated. Based on the NRI and NTI values, we found that $A O A$ and $A O B N R I$ and NTI values were above 2 in all reclaimed soils, except for the AOA community $(\mathrm{NTI}<2) 50$ years after soil reclamation and the AOB community (NTI > -2) in marsh soil (Figure S4). Most of the NRI and NTI values showed that populations of cooccurring ammonia oxidisers were more phylogenetically related than predicted by chance. In addition, in both communities, we correlated NTI and NRI values with environmental variables, including AN and TN, which were not significant. AOA NTI and NRI values were significantly and positively associated with $\mathrm{pH}$ $(P<0.01)$ and were not correlated negatively with $\mathrm{NO}_{3}{ }^{-}-\mathrm{N}(\mathrm{P}<0.01)$ EC and AK (Figure S5). AOB NTI and $\mathrm{NRI}$ values were negatively associated with $E C$ and $A K$, whereas other environmental factors were not significantly associated.

\section{Taxonomic and phylogenetic beta diversity analysis}

Distribution of the $\mathrm{AOA}$ and $\mathrm{AOB}$ community were distinct in later reclamation stages based on NMDS analysis (Fig. 3). The composition of ammonia oxidisers in the coastal salt marsh was significantly different from all reclaimed soils. Similarly, AOA and AOB communities 5 and 1000 years after soil reclamation also separated from other reclaimed soils. ANOSIM analysis revealed significant differences in $\mathrm{AOA}$ and $\mathrm{AOB}$ community composition (Table S2). The AOA community showed non-significant variations between T120 and T200 $(R=0.183, P=0.077), T 20$ and $T 50(R=-0.0260, P=0.571), T 60$ and $\mathrm{T} 120(\mathrm{R}=0.067, \mathrm{P}=0.206)$, and $\mathrm{T} 280$ and $\mathrm{T} 500(\mathrm{R}=-0.022, \mathrm{P}=0.546)$, indicating that temporal variations in the $A O A$ community were noted with a long reclamation time. The community structures of AOB were similar after 5-120 years of soil reclamation. The community structure of $A O B$ was not significant between T20 and T60 $(R=0.098, P=0.111), T 120$ and T200 $(R=0.107, P=0.188), T 60$ and $T 120(R=0.007, P=0.444)$, and $T 20$ and $T 50(R=0.119, P=0.157)$. The distance-based community dissimilarity (Weighted UniFrac distance) and BMNTD were used to measure the dissimilarity between different reclaimed soils. The weighted UniFrac values were greater than $\beta M N T D$, and both analyses showed that dissimilarity increased with the number of reclamation years (Fig. S6).

\section{Quantitative analysis of the ammonia-oxidising community assembly process}

The ammonia oxidiser community assembly process was calculated by the $\beta \mathrm{NTI}$ and $\mathrm{RC}_{\text {bray }}$ to reveal whether community assemblage mechanisms could explain the assembly process of ammonia oxidisers (Fig. 4). By counting the deviations of phylogenetic turnover, we found that $A O A$ and $A O B$ community assembly mechanisms showed that deterministic processes were dominant (84.71 and $55.2 \%$, respectively) with $\beta N T I$ were greater than 2 or less than -2 . The stochastic process was secondary 
(15.29 and $44.80 \%$, respectively) with $\beta N T I$ values between 2 and -2 . Variable selection contributed a larger fraction to the ammonia-oxidising community, followed by dispersal limitations. Furthermore, at each reclamation time, the AOB community in marsh soil and 60 years of reclaimed soil were assembled by stochastic processes ( 79.50 and $50.50 \%$, respectively), which were influenced by dispersal limitations (Table 2). Dispersal limitations and ecological drift (undominated processes) were secondary variables in the AOA community assembly process.

\section{Spatiotemporal variations in phylogenetic beta diversity and community composition}

The spatiotemporal variations in ammonia oxidiser community composition and phylogenetic beta diversity were analysed by weighted UniFrac dissimilarity, BMNTD, BNTI, and PERMANOVA based on ADONIS the Bray-Curtis distance. The PERMANOVA results showed that there were significant variations in archaeal and bacterial communities between salt marsh and reclaimed soils $(P<0.05)$ (Table S3). Between undisturbed salt marsh and reclaimed soils, the most considerable variations in community structure were noted $\left(F=26.8, R^{2}=0.73, P<0.001\right)$. Significant differences among reclaimed soils were found in $A O A$ and $A O B$ communities, while the maximum variation was noted in soils $50-500$ years after reclamation $\left(F=73.5, R^{2}=0.88\right.$ and $F=14.0, R^{2}=0.58$, respectively). $A O A$ and $A O B$ communities showed non-significant variations in reclaimed soils between adjacent close reclamation years $(P>0.05)$.

Temporal variations were detected $0-1000$ years after soil reclamation, indicating significant changes in the relative OTU composition. The weighted UPGMA cluster analysis indicated significant phylogenetic turnover in ammonia-oxidising prokaryotic community composition (Fig. S7A, B). Phylogenetic turnover at the phyla level in the AOA community from the coastal salt marsh to long-term reclaimed soil was associated with shifts in beta diversity composition, and $A O B$ community composition was not correlated with phylogenetic turnover. Based on BMNTD, we found that the dissimilarity of $A O A$ and $A O B$ communities increased with geographic distance and environmental variables (Fig. 5). To validate whether different geographic distance-controlled community assembly, we calculated the correlation between $\beta N T I$ values and spatial distance (Table S5). The results indicated that the deterministic process of geographic distance was greater than that of an environmental variable $(r=0.172, P=0.001$ and $r=$ $0.119, P=0.005)$ in the process of $A O A$ community assembly. In contrast, the AOB community was partially negatively correlated with environmental variables and geographic distance.

\section{Quantifying the roles of environmental variables and geographical distance in an ammonia oxidiser community}

To reveal the relationships between environmental variables and $A O A / A O B$ groups, canonical correspondence analysis (CCA) was conducted. The environmental variables (TN, SOM, $A N, \mathrm{NO}_{3}{ }^{-} \mathrm{N}$, available phosphorus $(A P) E C,, \mathrm{pH}, \mathrm{AK}$, and $\mathrm{NH}_{4}{ }^{+}-\mathrm{N}$ ) were selected based on their variance inflation factors (VIFs). They explained $57.4 \%$ and $58.8 \%$ of the variance in $A O A$ and AOB, respectively (Fig. 6A, B). Variance partition analysis (VPA) revealed that the relative influence of environmental and spatial parameters on the composition of $\mathrm{AOA}$ and $\mathrm{AOB}$ communities was $55.43 \%$ and $42.55 \%$ included geographic distance (7.25\% and $7.07 \%$ respectively). The community composition of AOA influenced by 
$\mathrm{NH}_{4}{ }^{+}-\mathrm{N}$ and $\mathrm{AOB}$ influenced by EC (3.66\% and 6.77\% respectively) (Fig. 6C, D). Spearman correlation coefficient analysis was used to correlate $A O A$ and $A O B$ phyla with environmental variables. Archaeal phylum Thaumarchaeota positively associated with $\mathrm{pH}$ and EC and negatively correlated with AP and $\mathrm{NO}_{3}{ }^{-} \mathrm{N}$. Furthermore, phylum Crenarchaeota was significantly and positively associated with TN and negatively associated with $\mathrm{NO}_{3}{ }^{-}-\mathrm{N}$ and $\mathrm{AK}$ (Table S4). The bacterial phylum Proteobacteria showed a positive correlation with $\mathrm{NH}_{4}{ }^{+}-\mathrm{N}, \mathrm{pH}, \mathrm{EC}$, and $\mathrm{AK}(\mathrm{P}<0.001)$ and a negative association with $\mathrm{SOM}, \mathrm{TN}$, and AN $(P<0.001)$. The $\beta N T I$ values were also correlated with environmental variables, indicating that AOA $\beta N T I$ was positively correlated with $\mathrm{EC}, \mathrm{AK}, \mathrm{AP}, \mathrm{NH}_{4}{ }^{+}-\mathrm{N}$, and $\mathrm{NO}_{3}{ }^{-} \mathrm{N}$ and negatively correlated $\mathrm{pH}$. The $A O B B N T I$ values were negatively associated with $E C$ and $A K$ and positively correlated with $\mathrm{pH}, \mathrm{AN}, \mathrm{AP}$, and $\mathrm{NH}_{4}{ }^{+}-\mathrm{N}$ (Fig. S8).

\section{Discussion}

\section{Succession of an ammonia-oxidising prokaryotic community along a coastal soil chronosequence}

Communities change in an orderly manner with time in a particular assumed environment, which is defined as succession [40]. Macro-ecologists have shifted their attention from standard vegetation description to the study of community dynamics, while micro-ecologists are still unable to develop a wellestablished framework to address microbes in successional environments [41]. Several studies have shown that the composition and distribution of microbial communities (fungal, archaeal, and bacterial) changes with temporal variations [42-44]. Salt marshes are particularly active ecosystems, and apart from their environmental significance, few studies have discussed the primary succession of microbial communities in these habitats to investigate the trends and processes at the phylogenetic level that drive archaeal, bacterial, and fungal assembly dynamics [45-48]. Although much of our understanding of the assembly and dynamics of the microbial community depends on taxonomy-based evaluations (i.e., based on the 16S rRNA gene), less focus has been devoted to the distribution in natural systems of functional genes. In the present study, we investigated the successional patterns AOA and AOB communities in an undisturbed salt marsh and reclaimed cultivated soil spanning 1000 years of ecosystem development, providing a unique and dynamic landscape to study the pattern of functional microbial communities. Some studies indicated that the archaeal amoA gene is more abundant than that of bacteria in marine and terrestrial environments [49-51]. Conversely, mounting evidence from various oceans and coasts has shown that the abundance of bacterial $a m o A$ genes in some regions is higher than that of archaeal $a m o A$ [52-54]. We showed that the archaeal amoA gene was more abundant in an undisturbed coastal salt marsh than the bacterial amoA. Along with reclamation years, archaeal amoA gene abundance significantly increased, while bacterial $a m o A$ gene abundance was asymmetrical and comparatively lower than that of archaea (Fig. 2). These findings suggested that the AOA amoA gene dominated not only costal marshes but also in reclaimed soil.

Marine $\mathrm{N}$ cycling by $\mathrm{AOA}$ and $\mathrm{AOB}$ can be affected by several factors, including physiochemical variables and external nutrient availability [55]. Here, we also found that abiotic parameters, including $\mathrm{EC}, \mathrm{pH}, \mathrm{NH}^{+}$ 
${ }_{4}^{-}{\mathrm{N}, \mathrm{NO}^{-}}_{3}-\mathrm{N}$, and SOM, had significant effects on the composition and diversity of ammonia oxidiser prokaryotic communities in reclaimed soils, which is an agreement with previous publications. For example, the availability of oxygen [56], phosphorus [57], $\mathrm{pH}$ [58], soil type [59], $\mathrm{NH}^{+}{ }_{4}{ }^{-} \mathrm{N}$, and $\mathrm{NO}^{-}{ }_{3}{ }^{-} \mathrm{N}$ [60] have been identified as essential parameters influencing the distribution and variety of ammoniaoxidising organisms in various habitats [61]. Previous studies indicated that AOA richness dominated in acidic soil, and $A O B$ dominated in neutral or alkaline soil [62]. The current study revealed that soil $\mathrm{pH}$ and ammonia-oxidising prokaryotic community $(\mathrm{AOA}$ and $\mathrm{AOB}$ ) richness continuously decreased with the succession of the soil, indicating that soil pH plays a vital role in ammonia-oxidising microbial composition. The changes in SOM, TN, and AN concentration in the soil environment were closely associated with dissimilarities in $A O B$ community composition [63]. It was previously shown that $A O A$ was more abundant in soil with lower concentrations of AN, while AOB increased correspondingly [64]. Our study showed that AN and SOM was significantly correlated with the AOB community in reclaimed soils. Moreover, the relative abundance of archaeal phylum Thaumarchaeota was positively correlated with $\mathrm{EC}$ and $\mathrm{pH}$, while Crenarchaeota was significantly and positively correlated with $\mathrm{TN}$. The bacterial amoA gene harboured in phylum Proteobacteria was positively correlated with $\mathrm{pH}, \mathrm{EC}, \mathrm{AK}$, and $\mathrm{NH}_{4}{ }^{+} \mathrm{N}$ and negatively correlated with TN, AN, and SOM concentration. Interestingly, both ammonia oxidiser communities responded differently to the number of reclamation years; therefore, both communities occupied separate ecological niches [14].

Our results suggest that differences in phylogenetic beta diversity of ammonia oxidiser communities could be described by temporal variability in nutrient availability $\left(\mathrm{NH}_{4}{ }^{+}-\mathrm{N}, \mathrm{SOM}, \mathrm{AP}\right.$, and $\left.\mathrm{AN}\right)$, as well as immigration of microbial input (uncultured bacterial species and uncultured prokaryotic accumulation), and the amplitude of variation in environmental factors ( $\mathrm{EC}$ and $\mathrm{pH})$ from coastal salt marshes to reclaimed cultivated soils. Soil buffering capacity and crops became more dominant as succession proceeded, which possibly reduced the amplitude of variations, resulting in the reduction of phylogenetic turnover in AOB (Fig. 5). These temporal effects were further correlated with edaphic factors from coastal salt marshes to long-term reclaimed soils, indicating that the AOA community was dominantly driven by environmental variables compared to the AOB community (Fig. S4). Archaeal and bacterial richness continuously decreased from coastal salt marshes to long-term reclaimed cultivated soils, while the accumulation of uncultured bacteria species was observed at later reclamation stages. Phylogenetic diverse ammonia oxidiser taxa were observed at later stages than at primary reclamation stages; therefore, our study supports 'the theorem of diversity begets diversity' [65], which assumes community evolution towards species complexity.

\section{Deterministic processes determine the assembly of ammonia oxidiser communities}

Assembly processes that form the community's structure have recently been of considerable interest [66, 67]. Particularly for the long-term time scale, it is essential to consider the drivers influencing ecological succession in response to environmental disturbance [68]. It has previously been stated that stochasticity 
has been reduced across successive phases [69, 70], but there was no improvement in the assembly mechanism during succession based on the time scale. According to niche-based theory, deterministic factors, including species traits, interspecies interactions, and environmental conditions, govern community structure [71]. Our study showed that AOA and AOB communities were assembled by deterministic process (84.71 and $55.2 \%$, respectively), as well as reclamation of coastal marshes. Our results are contradictory with previously reported studies; the pattern of increasing deterministic process might be due to long-term reclamation of coastal salt marshes over 1000 years, while previous studies demonstrated that short successional stages (more than one century) [69, 72], artificial soil disturbance, and cropping system also influence the deterministic process [73]. A study reported that spatial distance had a significant role in the soil bacterial community [73], and our study also revealed that spatial distance (geographic and environmental) was significantly correlated with AOA and AOB community structure. In our study, the AOA community was positively correlated with geographic and environmental distance, while the $A O B$ community was negatively associated with environmental distance and partially correlated with geographic distance. The unmeasured environmental variables also affected phylogenetic community assembly. Previous studies have shown that unmeasured environmental factors have an intensifying impact on deterministic processes that suppress stochastic processes [74]. Our AOB community results showed that phylogenetic turnover is associated with geographical distance instead of environmental variables; therefore, deterministic processes are dominant compared to stochastic processes, which supports the argument given by [75]. Other studies have shown that as geographic distance increases, if phylogenetic turnover also increases, it will significantly influence deterministic processes [74]. In this study, the heterogeneous community selection of AOA was strongly associated with geographical distance. $\beta N T I$ correlations with environmental variables indicated that $E C$ and $A K$ were negatively related to the $\mathrm{AOB}$ community, while $\mathrm{AOA}$ community was partially negatively correlated with $\mathrm{pH}$.

\section{Spatiotemporal variations in ecosystem function and its relationship with environmental variables and abundance of $A O A$ and $A O B$}

Nitrification rate and nitrogen mineralisation rate are fundamental indicators for soil to supply nitrogen for plant growth and nitrogen transformation in the environment [76]. Previous studies indicated that ammonia oxidation was higher in acidic soils with AOA, while bacterial ammonia oxidation was higher in neutral or alkaline soils [77-79]. We found that $\mathrm{pH}$ decreased from alkaline to neutral with the reclamation of coastal salt marshes, and the relative abundance of the $a m o A$ gene and nitrification rate was higher in archaea compared to the bacterial community. In addition to soil pH, the availability of nutritional gradients SOM and TN played important roles in the nitrification rate [80-82]. The cultivation of crops and utilisation of fertiliser increased soil organic matter and total nitrogen, and a similar trend was observed in our study, suggesting that land management practices, i.e., reclamation of salt marshes to cultivated soil increased soil organic matter and total nitrogen. Both of these factors might contribute to the nitrification rate in agricultural soil [83]. Another study indicated that the ammonium concentration is the key factor determining the relative contribution of $A O B$ and $A O A$ in nitrification in agricultural soils [84]. Our study presented contradictory findings that ammonium concentration was not correlated with 
nitrification rate (Table S1). Interestingly, ammonium concentration was also not associated with AOA community distribution and amoA gene abundance (Table S1 \& S5), which might be due to the potential nitrification rate that is also not correlated to ammonium concentration, as AOA plays a significant role in nitrification in agricultural soils compare to AOB [21].

In a grassland ecosystem, nitrogen mineralisation is affected by biotic (animal, soil microbes, and plant) and abiotic (environmental variations and anthropogenic disturbance) factors [85, 86]. In previous studies on grassland soils, the net nitrogen mineralisation and net nitrification rate showed a similar trend [87]; our contradictory findings showed that the net nitrogen mineralisation rate showed an opposite trend in reclaimed soil. Previous studies revealed that the AOB community was positively correlated with nitrogen mineralisation rate in agricultural land [88], but we found that net nitrogen mineralisation rate was not correlated with bacterial $a m o A$ gene abundance. In long-term reclamation, for AOA, amoA gene abundance and nitrification rates accumulated, indicating that $A O A$ was the dominant nitrifying community. Notably, the comammox organism's discovery and their high amoA gene richness in different soils suggested that they are functionally related to soil nitrification, thereby modifying the contribution of ammonia-oxidising archaea and bacteria to the nitrification rate [89]. Thus, net nitrogen mineralisation and potential nitrification rates were influenced by environmental factors, reclamation years, and AOA community.

\section{Conclusion}

We investigated temporal and spatial variations in an ammonia oxidiser community from a coastal salt marsh (0 years) and long-term (1000 years) reclaimed soils and observed the heterogenicity of diversity, composition, and phylogenetic structure of $A O A$ and $A O B$ communities. During the 1000 years of reclamation, there was a clear evolution of the $a m o A$ gene harboured in $A O A$ and $A O B$ communities. The soil ecosystem was significantly destroyed by the reclamation of coastal wetlands, which also altered soil physicochemical parameters. We investigated the relative importance of stochastic and deterministic processes in shaping $\mathrm{AOA}$ and $\mathrm{AOB}$ communities. In the assembly of ammonia oxidiser groups, deterministic processes were dominant over stochastic processes. The major soil physicochemical parameter changes included a decrease in $\mathrm{pH}, \mathrm{EC}$, and $\mathrm{NH}_{4}{ }^{+}-\mathrm{N}$ and increase of SOM, AN, and TN. A decrease in substrate concentration and $\mathrm{pH}$ subsequently led to a decrease in ammonia oxidiser prokaryotic communities. Temporal differences in soil ecosystem functioning, including nitrification potential rate and net nitrogen mineralisation rate, were also found, suggesting that reclamation from coastal salt marshes to cultivated soil increased the soil nitrification activity. These findings provide a better understanding of how soil $\mathrm{N}$ cycling, reclamation of coastal salt marshes, long-term land management, and cultivation of crops affect ammonia-oxidising communities, including assembly dynamics, amoA gene abundance, and community distribution patterns.

\section{List Of Abbreviations}

AOA: Ammonia Oxidising Archaea 
AOB: Ammonia Oxidising Bacteria

FAO/UNESCO: Food and Agriculture Organization/United Nations Educational, Scientific and Cultural Organization

$\mathrm{N}$ : Nitrogen

PCR: Polymerase Chain Reaction

qPCR: quantitative Polymerase Chain Reaction

OTUs: Operational Taxonomic Unit

EC: Electron Conductivity

AK: Available Potassium

SOM: Soil Organic Matter

AN: Available Nitrogen

TN: Total Nitrogen

AP: Available Phosphorous

PD: Faith Phylogene1c Diversity

VIFs: Variance Inflation Factors

VPA: Variance Partition Analysis

MPD: Mean Phylogenetic Distance

NRI: Net Relatedness Index

MNTD: Mean Nearest Taxon Distance

NTI: Net Taxon Index

BMNTD: beta Mean Nearest Taxon Distance

BNTI: beta Net Taxon Index

ANOVA: Analysis Of Variance

NMDS: Non-metric Multi-Dimensional Scaling

PERMANOVA: Permutational Multivariate Analysis Of Variation 
CCA: Canonical Correspondence Analysis

RCbray: Bray-Curtis-based Raup-Crick metric

ANOSIM: Analysis of Similarity

UPGMA: Unweighted pair group method with arithmetic mean

\section{Declarations}

\section{Ethics approval and consent to participate}

Not applicable

\section{Consent for publication}

Not applicable

\section{Availability of data and material}

All data supporting the findings of this study are available on request from the corresponding authors (Hui Cao, Feng Wang).

\section{Competing interests}

The authors declare that they have no competing interests.

\section{Funding}

This work was financially supported by the National Natural Science Foundation of China $(41501279,42077026)$ and National Key Research and Development Program of China (2016YFD0200800).

\section{Authors' contributions}

S.H. and Y.Y. were major contributors in manuscript writing, analysed sequence data and prepared figures and/or tables. S.L. contributed in reagents/material/analysis. S.Y. analysed the physiochemical parameters. D.C. contributed in sample collection and performed qPCR. C.H. and W.F. conceived and developed the original framework, reviewed drafts of the paper, approved the final draft. All authors read and approved the final manuscript.

\section{Acknowledgements}

We thank Prof. Xiong You for their valuable advice on data analysis. 


\section{References}

1. Gutknecht JL, Field CB, Balser TC: Microbial communities and their responses to simulated global change fluctuate greatly over multiple years. Global Change Biology 2012, 18:2256-2269.

2. Hutchins DA, Fu F: Microorganisms and ocean global change. Nature microbiology 2017, 2:17058.

3. Zhou J, Ning D: Stochastic community assembly: does it matter in microbial ecology? Microbio/ Mol Biol Rev 2017, 81:e00002-00017.

4. Hanson CA, Fuhrman JA, Horner-Devine MC, Martiny JB: Beyond biogeographic patterns: processes shaping the microbial landscape. Nat Rev Microbiol 2012, 10:497-506.

5. Chase JM, Leibold MA: Ecological niches: linking classical and contemporary approaches. University of Chicago Press; 2003.

6. Van der Maarel E, Franklin J: Vegetation ecology. John Wiley \& Sons; 2012.

7. Tilman D: Plant Strategies and the Dynamics and Structure of Plant Communities. Princeton University Press; 1988.

8. Deegan LA, Johnson DS, Warren RS, Peterson BJ, Fleeger JW, Fagherazzi S, Wollheim WM: Coastal eutrophication as a driver of salt marsh loss. Nature 2012, 490:388-392.

9. Bowen J, Byrnes J, Weisman D, Colaneri C: Functional gene pyrosequencing and network analysis: an approach to examine the response of denitrifying bacteria to increased nitrogen supply in salt marsh sediments. Frontiers in Microbiology 2013, 4.

10. Sousa Al, Lillebø Al, Caçador I, Pardal MA: Contribution of Spartina maritima to the reduction of eutrophication in estuarine systems. Environmental Pollution 2008, 156:628-635.

11. Verhoeven JT, Arheimer B, Yin C, Hefting MM: Regional and global concerns over wetlands and water quality. Trends in ecology \& evolution 2006, 21:96-103.

12. Rotthauwe J-H, Witzel K-P, Liesack W: The ammonia monooxygenase structural gene amoA as a functional marker: molecular fine-scale analysis of natural ammonia-oxidizing populations. App/ Environ Microbiol 1997, 63:4704-4712.

13. Zhang $Y, X u$ J, Riera N, Jin T, Li J, Wang N: Huanglongbing impairs the rhizosphere-to-rhizoplane enrichment process of the citrus root-associated microbiome. Microbiome 2017, 5:97.

14. Brankatschk R, Töwe S, Kleineidam K, Schloter M, Zeyer J: Abundances and potential activities of nitrogen cycling microbial communities along a chronosequence of a glacier forefield. The ISME journal 2011, 5:1025-1037.

15. Sigler W, Zeyer J: Microbial diversity and activity along the forefields of two receding glaciers. Microbial Ecology 2002:397-407.

16. Nemergut DR, Anderson SP, Cleveland CC, Martin AP, Miller AE, Seimon A, Schmidt SK: Microbial community succession in an unvegetated, recently deglaciated soil. Microbial ecology 2007, 53:110122. 
17. Ferrenberg S, O'neill SP, Knelman JE, Todd B, Duggan S, Bradley D, Robinson T, Schmidt SK, Townsend AR, Williams MW: Changes in assembly processes in soil bacterial communities following a wildfire disturbance. The ISME journal 2013, 7:1102-1111.

18. Dini-Andreote F, Stegen JC, van Elsas JD, Salles JF: Disentangling mechanisms that mediate the balance between stochastic and deterministic processes in microbial succession. Proceedings of the National Academy of Sciences 2015, 112:E1326-E1332.

19. Hüttl RF, Weber E: Forest ecosystem development in post-mining landscapes: a case study of the Lusatian lignite district. Naturwissenschaften 2001, 88:322-329.

20. Kuramae EE, Gamper HA, Yergeau E, Piceno YM, Brodie EL, DeSantis TZ, Andersen GL, Van Veen JA, Kowalchuk GA: Microbial secondary succession in a chronosequence of chalk grasslands. The ISME journal 2010, 4:711-715.

21. Wu X, Zhang W, Liu G, Yang X, Hu P, Chen T, Zhang G, Li Z: Bacterial diversity in the foreland of the Tianshan No. 1 glacier, China. Environmental Research Letters 2012, 7:014038.

22. Walker LR, Wardle DA, Bardgett RD, Clarkson BD: The use of chronosequences in studies of ecological succession and soil development. Journal of ecology 2010, 98:725-736.

23. Guo Z-g, Yang Z-s, Qu Y-h, Fan D-j: Study on comparison sedimentary geochemistry of mud area on East China Sea continental shelf. Acta Sedimentologica Sinica 2000, 18:284-289.

24. Cheng Y-Q, Yang L-Z, Cao Z-H, Ci E, Yin S: Chronosequential changes of selected pedogenic properties in paddy soils as compared with non-paddy soils. Geoderma 2009, 151:31-41.

25. Roth PJ, Lehndorff E, Cao Zh, Zhuang S, Bannert A, Wissing L, Schloter M, Kögel-Knabner I, Amelung W: Accumulation of nitrogen and microbial residues during 2000 years of rice paddy and non-paddy soil development in the Y angtze R iver D elta, C hina. Global Change Biology 2011, 17:3405-3417.

26. Martin M: Cutadapt removes adapter sequences from high-throughput sequencing reads. EMBnet journal 2011, 17:10-12.

27. Haas BJ, Gevers D, Earl AM, Feldgarden M, Ward DV, Giannoukos G, Ciulla D, Tabbaa D, Highlander SK, Sodergren E: Chimeric 16S rRNA sequence formation and detection in Sanger and 454pyrosequenced PCR amplicons. Genome research 2011, 21:494-504.

28. Edgar RC, Haas BJ, Clemente JC, Quince C, Knight R: UCHIME improves sensitivity and speed of chimera detection. Bioinformatics 2011, 27:2194-2200.

29. Edgar RC: UPARSE: highly accurate OTU sequences from microbial amplicon reads. Nature methods 2013, 10:996.

30. Yang S, Liebner S, Alawi M, Ebenhöh O, Wagner D: Taxonomic database and cut-off value for processing mcrA gene 454 pyrosequencing data by MOTHUR. Journal of microbiological methods 2014, 103:3-5.

31. Edgar RC: MUSCLE: multiple sequence alignment with high accuracy and high throughput. Nucleic acids research 2004, 32:1792-1797. 
32. Webb CO: Exploring the Phylogenetic Structure of Ecological Communities: An Example for Rain Forest Trees. American Naturalist 2000, 156:145-155.

33. Kembel SW: Disentangling niche and neutral influences on community assembly: assessing the performance of community phylogenetic structure tests. Ecology Letters 2010, 12:949-960.

34. Stegen JC, Lin X, Konopka AE, Fredrickson JK: Stochastic and deterministic assembly processes in subsurface microbial communities. Isme Journal 2012, 6:1653-1664.

35. Zhang C-J, Pan J, Duan C-H, Wang Y-M, Liu Y, Sun J, Zhou H-C, Song X, Li M: Prokaryotic Diversity in Mangrove Sediments across Southeastern China Fundamentally Differs from That in Other Biomes. mSystems 2019, 4:e00442-00419.

36. White JR, Nagarajan N, Pop M: Statistical methods for detecting differentially abundant features in clinical metagenomic samples. PLoS computational biology 2009, 5.

37. Hardy OJ: Testing the spatial phylogenetic structure of local communities: statistical performances of different null models and test statistics on a locally neutral community. Journal of Ecology 2008, 96:914-926.

38. Stegen JC, Lin X, Fredrickson JK, Chen X, Kennedy DW, Murray CJ, Rockhold ML, Konopka A: Quantifying community assembly processes and identifying features that impose them. Isme $j 2013$, 7:2069-2079.

39. Stegen JC, Lin X, Fredrickson JK, Konopka AE: Estimating and mapping ecological processes influencing microbial community assembly. Frontiers in Microbiology 2015, 6.

40. Begon M, Harper J, Townsend C: Ecology: individuals, populations, and communities. Blackwell Scientific. Boston, Massachusetts 1996.

41. Fierer $N$, Nemergut $D$, Knight R, Craine JM: Changes through time: integrating microorganisms into the study of succession. Research in microbiology 2010, 161:635-642.

42. Li J, Pu L, Zhu M, Zhang J, Li P, Dai X, Xu Y, Liu L: Evolution of soil properties following reclamation in coastal areas: A review. Geoderma 2014, 226:130-139.

43. Anderson JD, Ingram LJ, Stahl PD: Influence of reclamation management practices on microbial biomass carbon and soil organic carbon accumulation in semiarid mined lands of Wyoming. Applied Soil Ecology 2008, 40:387-397.

44. Dimitriu PA, Prescott CE, Quideau SA, Grayston SJ: Impact of reclamation of surface-mined boreal forest soils on microbial community composition and function. Soil Biology and Biochemistry 2010, 42:2289-2297.

45. Keith-Roach MJ, Bryan ND, Bardgett RD, Livens FR: Seasonal changes in the microbial community of a salt marsh, measured by phospholipid fatty acid analysis. Biogeochemistry 2002, 60:77-96.

46. Liu J, Zhu S, Liu X, Yao P, Ge T, Zhang X-H: Spatiotemporal dynamics of the archaeal community in coastal sediments: assembly process and co-occurrence relationship. The ISME Journal 2020, 14:1463-1478. 
47. Bowen JL, Crump BC, Deegan LA, Hobbie JE: Salt marsh sediment bacteria: their distribution and response to external nutrient inputs. The ISME Journal 2009, 3:924-934.

48. Salles JF, Pereira e Silva MC, Dini-Andreote F, Dias ACF, Guillaumaud N, Poly F, van Elsas JD: Successional patterns of key genes and processes involved in the microbial nitrogen cycle in a salt marsh chronosequence. Biogeochemistry 2017, 132:185-201.

49. Shen JE, Zhang LE, Zhu Y, Zhang JB, He JH: Abundance and composition of ammonia区xidizing bacteria and ammonia『xidizing archaea communities of an alkaline sandy loam. Environmental Microbiology 2008, 10.

50. Leininger S, Urich T, Schloter M, Schwark L, Qi J, Nicol GW, Prosser JI, Schuster SC, Schleper C: Archaea predominate among ammonia-oxidizing prokaryotes in soils. Nature 2006, 442:806-809.

51. Mincer TJ, Church MJ, Taylor LT, Preston C, Karl DM, DeLong EF: Quantitative distribution of presumptive archaeal and bacterial nitrifiers in Monterey Bay and the North Pacific Subtropical Gyre. Environmental Microbiology 2007, 9:1162-1175.

52. Caffrey JM, Bano N, Kalanetra K, Hollibaugh JT: Ammonia oxidation and ammonia-oxidizing bacteria and archaea from estuaries with differing histories of hypoxia. Isme Journal 2007, 1:660.

53. Mosier AC, Francis CA: Relative abundance and diversity of ammonia-oxidizing archaea and bacteria in the San Francisco Bay estuary. Environmental Microbiology 2008, 10:3002-3016.

54. Santoro AE, Francis CA, Sieyes NRD, Boehm AB: Shifts in the relative abundance of ammoniaoxidizing bacteria and archaea across physicochemical gradients in a subterranean estuary. 2008, 10:1068-1079.

55. Bowen, J. L, Crump, B. C, Deegan, L. A, Hobbie, J. E: Salt marsh sediment bacteria: their distribution and response to external nutrient inputs. Isme Journa/ 2009.

56. Gleeson DB, Müller C, Banerjee S, Ma W, Siciliano SD, Murphy DV: Response of ammonia oxidizing archaea and bacteria to changing water filled pore space. Soil Biology and Biochemistry 2010, 42:1888-1891.

57. Herfort L, Schouten S, Abbas B, Veldhuis MJW, Coolen MJL, Wuchter C, Boon JP, Herndl GJ, Sinninghe Damsté JS: Variations in spatial and temporal distribution of Archaea in the North Sea in relation to environmental variables. FEMS Microbiology Ecology 2007, 62:242-257.

58. Li H, Weng B-S, Huang F-Y, Su J-Q, Yang X-R: pH regulates ammonia-oxidizing bacteria and archaea in paddy soils in Southern China. Applied Microbiology and Biotechnology 2015, 99:6113-6123.

59. Huang R, Wu Y, Zhang J, Zhong W, Jia Z, Cai Z: Nitrification activity and putative ammonia-oxidizing archaea in acidic red soils. Journal of Soils and Sediments 2012, 12:420-428.

60. Li X-r, Xiao Y-p, Ren W-w, Liu Z-f, Shi J-h, Quan Z-x: Abundance and composition of ammoniaoxidizing bacteria and archaea in different types of soil in the Yangtze River estuary. Journal of Zhejiang University SCIENCE B 2012, 13:769-782.

61. Behrendt T, Braker G, Song G, Pommerenke B, Dörsch P: Nitric oxide emission response to soil moisture is linked to transcriptional activity of functional microbial groups. Soil Biology and Biochemistry 2017, 115:337-345. 
62. Nicol GW, Leininger S, Schleper C, Prosser JI: The influence of soil pH on the diversity, abundance and transcriptional activity of ammonia oxidizing archaea and bacteria. Environ Microbio/ 2008, 10:2966-2978.

63. Yang D, Xiao X, He N, Zhu W, Liu M, Xie G: Effects of reducing chemical fertilizer combined with organic amendments on ammonia-oxidizing bacteria and archaea communities in a low-fertility red paddy field. Environmental Science and Pollution Research 2020, 27:29422-29432.

64. Jia Z, Conrad R: Bacteria rather than Archaea dominate microbial ammonia oxidation in an agricultural soil. Environmental Microbiology 2009, 11:1658-1671.

65. Whittaker RH: Evolution and Measurement of Species Diversity. Taxon 1972, 21:213-251.

66. Zhou J, Ning D: Stochastic Community Assembly: Does It Matter in Microbial Ecology? Microbiology and Molecular Biology Reviews 2017, 81:e00002-00017.

67. Chase JM: Stochastic Community Assembly Causes Higher Biodiversity in More Productive Environments. Science 2010, 328:1388-1391.

68. Chang $\mathrm{C}$, Hillerislambers $\mathrm{J}$ : Integrating succession and community assembly perspectives. Other 2016, 5.

69. Dini-Andreote F, Stegen JC, van Elsas JD, Salles JF: Disentangling mechanisms that mediate the balance between stochastic and deterministic processes in microbial succession. Proc Natl Acad Sci US A 2015, 112:E1326-1332.

70. Tripathi BM, Stegen JC, Kim M, Dong K, Adams JM, Lee YK: Soil pH mediates the balance between stochastic and deterministic assembly of bacteria. The ISME Journal 2018, 12:1072-1083.

71. Chesson P: Mechanisms of Maintenance of Species Diversity. Annual Review of Ecology and Systematics 2000, 31:343-366.

72. Liang Y, Ning D, Lu Z, Zhang N, Hale L, Wu L, Clark IM, McGrath SP, Storkey J, Hirsch PR, et al: Century long fertilization reduces stochasticity controlling grassland microbial community succession. Soil Biology and Biochemistry 2020, 151:108023.

73. Jiang $L$, Patel $S N$ : Community assembly in the presence of disturbance: a microcosm experiment. Ecology 2008, 89:1931-1940.

74. Wang J, Shen J, Wu Y, Tu C, Soininen J, Stegen JC, He J, Liu X, Zhang L, Zhang E: Phylogenetic beta diversity in bacterial assemblages across ecosystems: deterministic versus stochastic processes. The ISME Journal 2013, 7:1310-1321.

75. Stegen JC, Hurlbert AH: Inferring Ecological Processes from Taxonomic, Phylogenetic and Functional Trait $\beta$-Diversity. PLOS ONE 2011, 6:e20906.

76. Neill C, Piccolo MC, Steudler PA, Melillo JM, Feigl BJ, Cerri CC: Nitrogen dynamics in soils of forests and active pastures in the western Brazilian Amazon Basin. Soil Biology and Biochemistry 1995, 27:1167-1175.

77. Lehtovirta LE, Prosser JI, Nicol GW: Soil pH regulates the abundance and diversity of Group $1.1 \mathrm{c}$ Crenarchaeota. FEMS Microbiology Ecology 2009, 70:367-376. 
78. Leininger S, Urich T, Schloter M, Schwark L, Qi J, Nicol GW, Prosser JI, Schuster S, Schleper C: Archaea predominate among ammonia-oxidizing prokaryotes in soils. Nature 2006, 442:806-809.

79. Erguder TH, Boon N, Wittebolle L, Marzorati M, Verstraete W: Environmental factors shaping the ecological niches of ammonia-oxidizing archaea. FEMS microbiology reviews 2009, 33:855-869.

80. Yao H, Gao Y, Nicol GW, Campbell CD, Prosser JI, Zhang L, Han W, Singh BK: Links between ammonia oxidizer community structure, abundance, and nitrification potential in acidic soils. Applied and environmental microbiology 2011, 77:4618-4625.

81. Dai L, Liu C, Yu L, Song C, Peng L, Li X, Tao L, Li G: Organic Matter Regulates Ammonia-Oxidizing Bacterial and Archaeal Communities in the Surface Sediments of Ctenopharyngodon idellus Aquaculture Ponds. Frontiers in Microbiology 2018, 9.

82. Zhou X, Fornara D, Wasson EA, Wang D, Ren G, Christie P, Jia Z: Effects of 44 years of chronic nitrogen fertilization on the soil nitrifying community of permanent grassland. Soil Biology and Biochemistry 2015, 91:76-83.

83. Wessén E, Nyberg K, Jansson JK, Hallin S: Responses of bacterial and archaeal ammonia oxidizers to soil organic and fertilizer amendments under long-term management. Applied Soil Ecology 2010, 45:193-200.

84. Ouyang Y, Norton JM, Stark JM: Ammonium availability and temperature control contributions of ammonia oxidizing bacteria and archaea to nitrification in an agricultural soil. Soil Biology and Biochemistry 2017, 113:161-172.

85. Wang $\mathrm{C}$, Xing $\mathrm{X}$, Han $\mathrm{X}$ : Advances in study of factors affecting soil $\mathbf{N}$ mineralization in grassland ecosystems. Ying yong sheng tai xue bao= The journal of applied ecology 2004, 15:2184.

86. Tripathi N, Singh RS: Cultivation impacts nitrogen transformation in Indian forest ecosystems. Nutrient Cycling in Agroecosystems 2007, 77:233-243.

87. Zhang S, Chen D, Sun D, Wang X, Smith JL, Du G: Impacts of altitude and position on the rates of soil nitrogen mineralization and nitrification in alpine meadows on the eastern Qinghai-Tibetan Plateau, China. Biology and Fertility of Soils 2012, 48:393-400.

88. Risch AC, Zimmermann S, Ochoa-Hueso R, Schütz M, Frey B, Firn JL, Fay PA, Hagedorn F, Borer ET, Seabloom EW, et al: Soil net nitrogen mineralisation across global grasslands. Nature Communications 2019, 10:4981.

89. Pjevac P, Schauberger C, Poghosyan L, Herbold CW, van Kessel MAHJ, Daebeler A, Steinberger M, Jetten MSM, Lücker S, Wagner M, Daims H: AmoA-Targeted Polymerase Chain Reaction Primers for the Specific Detection and Quantification of Comammox Nitrospira in the Environment. Frontiers in Microbiology 2017, 8.

\section{Tables}


Table. 1. The alpha diversity of AOA and AOB community along soil chronosequence.

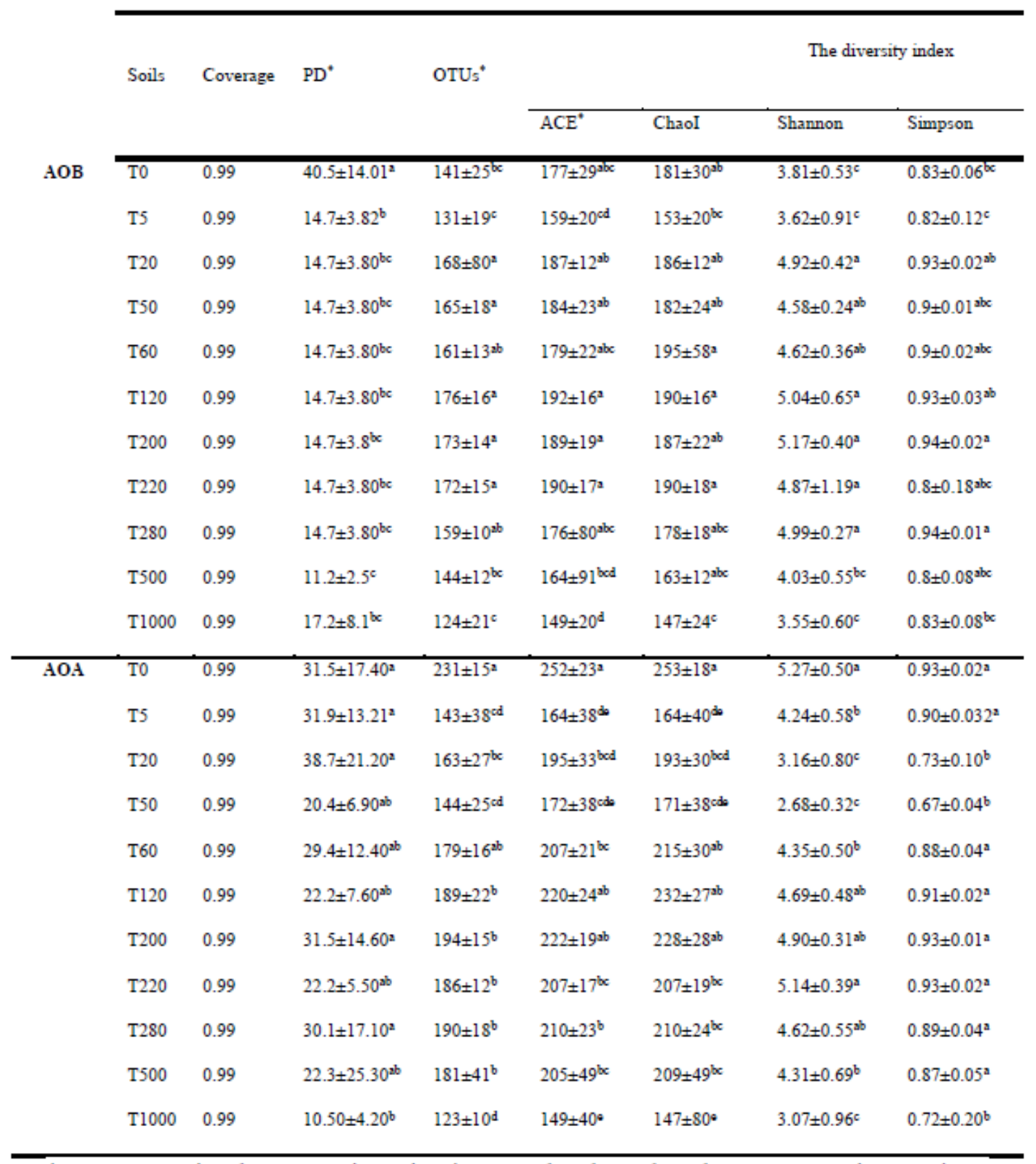

\footnotetext{
*OTU: Operational Taxonomic Units, *ACE: Abundance-based Coverage Estimator, *PD: Phylogenetic diversity. Note: Values are means \pm standard deviation $(\mathrm{n}=6)$, and the superscripts of different letters in the same column indicated that there were significant differences (Duncan's test, $\mathrm{P}<0.05$ ) among soil samples.
} 
Table. 2. The relative importance (\%) of each assembly process that governs the turnover of ammonia oxidising community.

Assembly Process

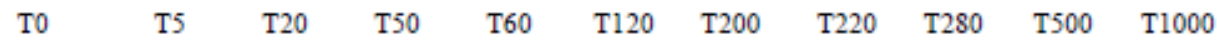

AOA

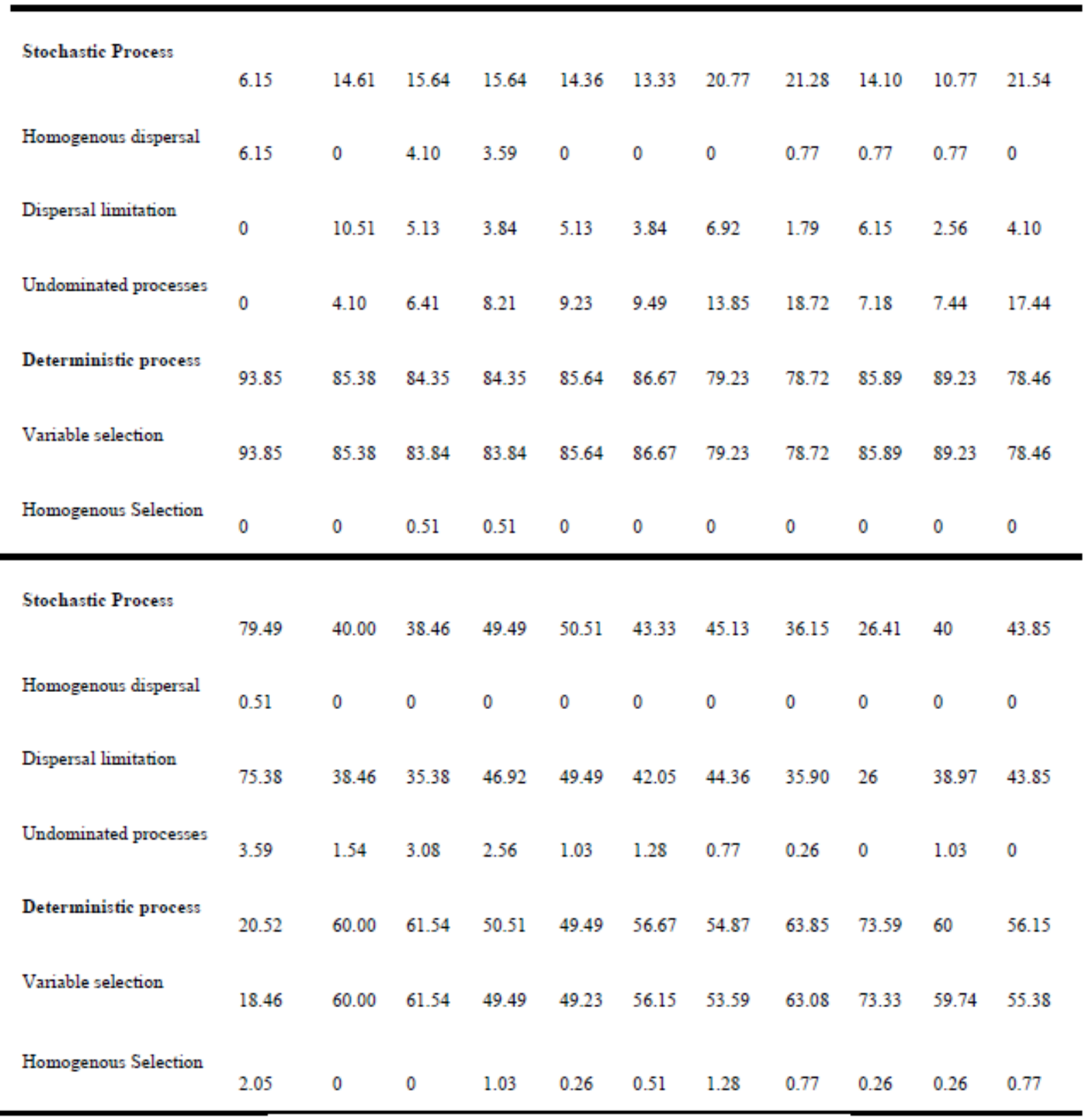

Note: Stochastic process, $|\beta N T I|<2$; Deterministic process, $\beta$ NTI $>2$ or $\beta$ NTI $<-2$.

Figures 
(A)

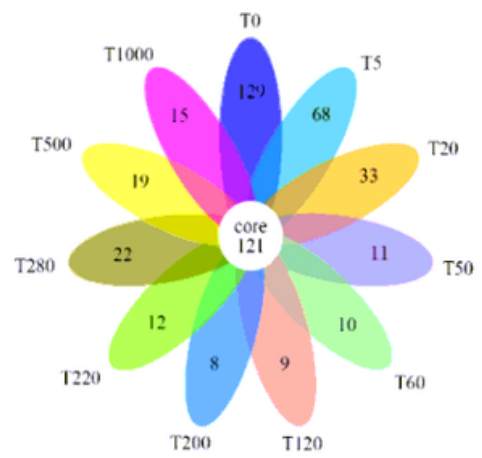

(C)

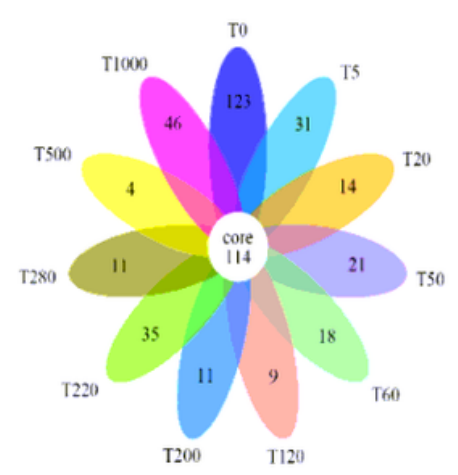

(B)

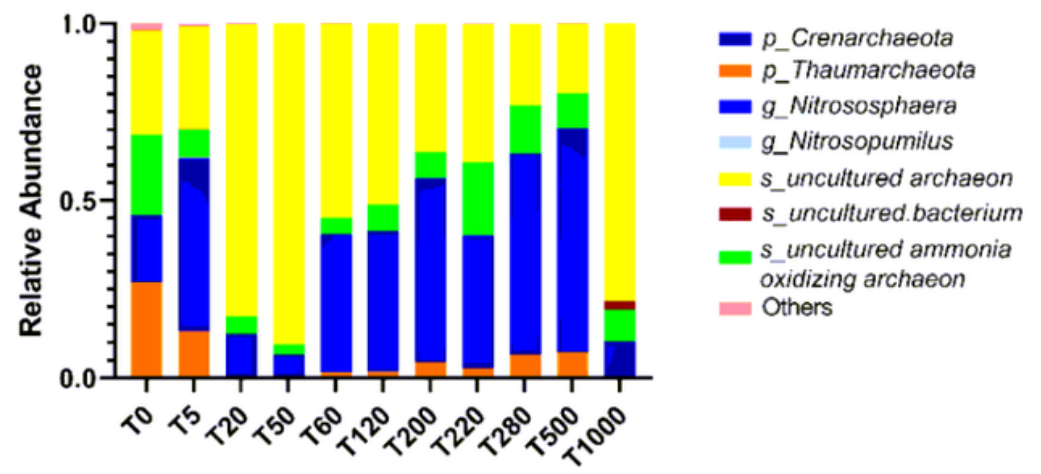

(D)

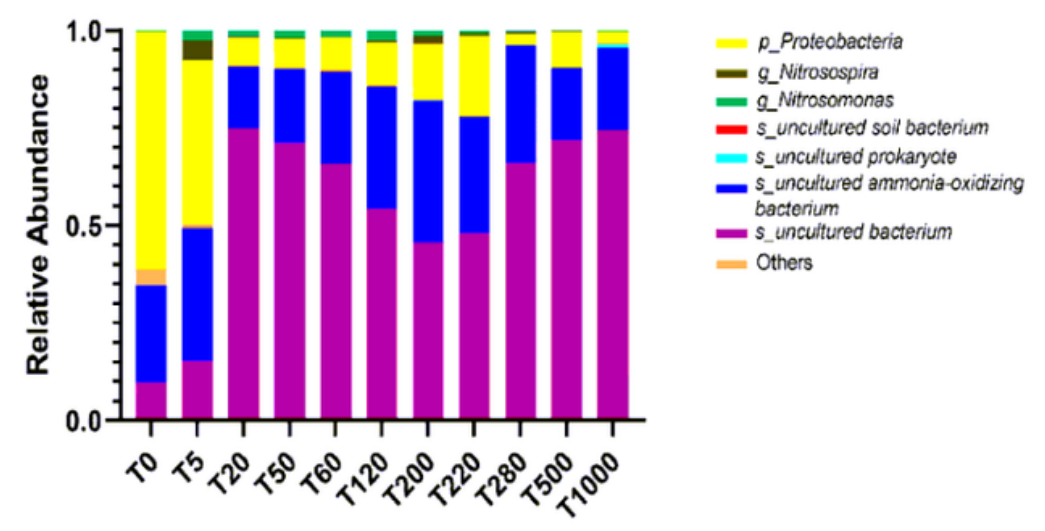

\section{Figure 1}

Ammonia oxidizer community composition among soil chronosequence. (A) petal map of shared and unique AOA OTUs in different soil samples $(n=66)$, (B) composition of ammonia-oxidizing archaea among reclaimed soils, (C) petal map of shared and unique AOB OTUs, (D) composition of ammoniaoxidizing bacteria among chronosequence. 
(A)

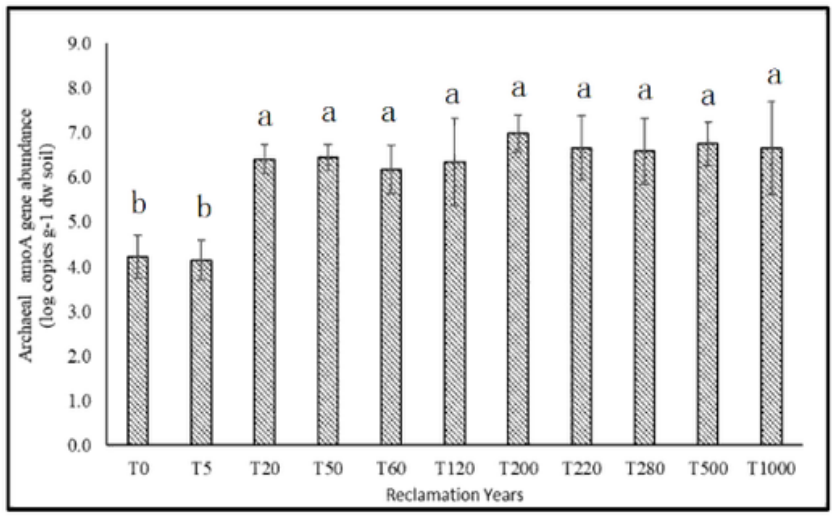

(C)

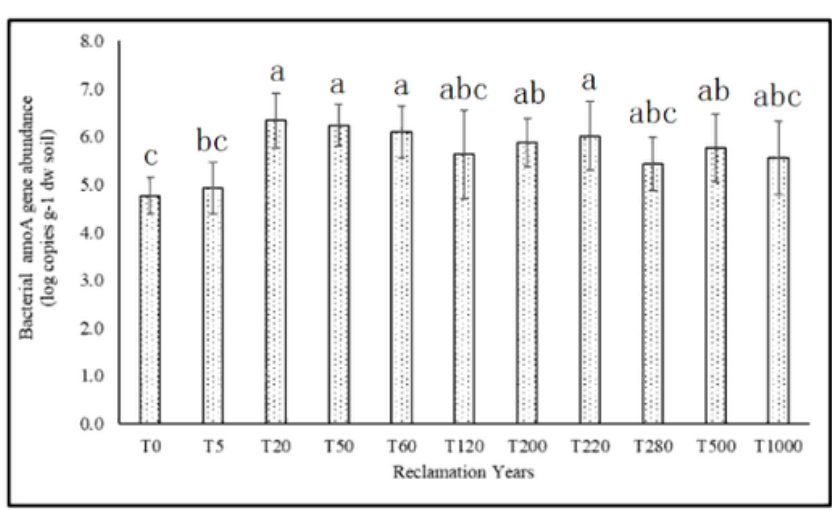

(B)

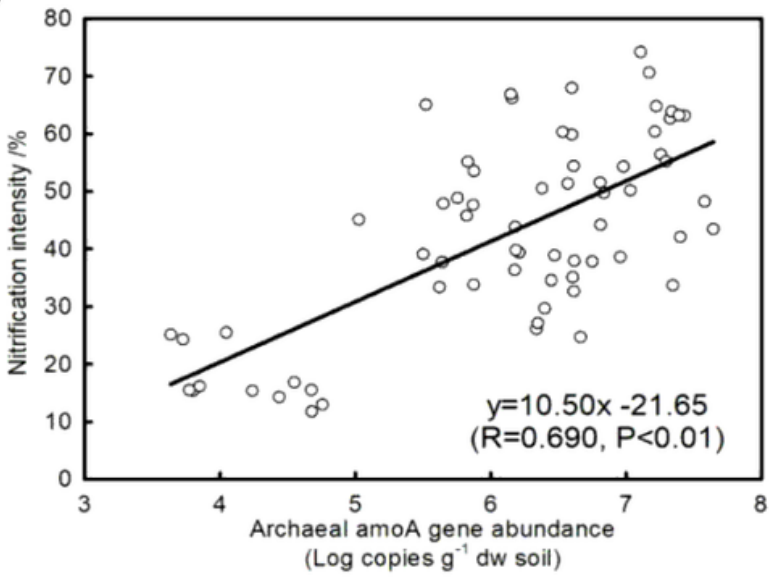

(D)

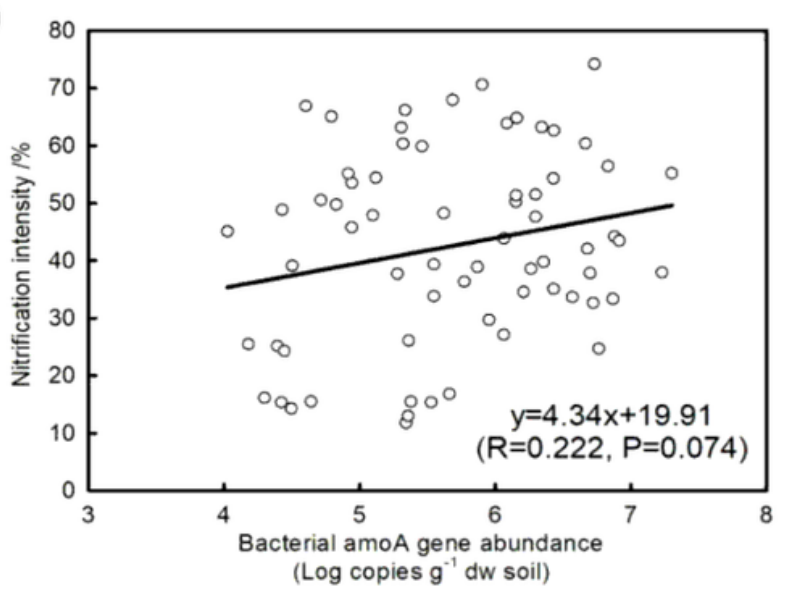

Figure 2

Histogram of quantitative archaeal and bacterial aomA gene abundance per gram dry soil. (A) archaeal amoA gene abundance, (B) correlation analysis of archaeal amoA gene abundance with nitrification rate, (C) archaeal amoA gene abundance, (D) correlation analysis of bacterial amoA gene abundance with nitrification rate. Bars labelled with different superscript letters indicate a significant difference (Duncan's test, $\mathrm{P}<0.05)$ among reclamation stages. 

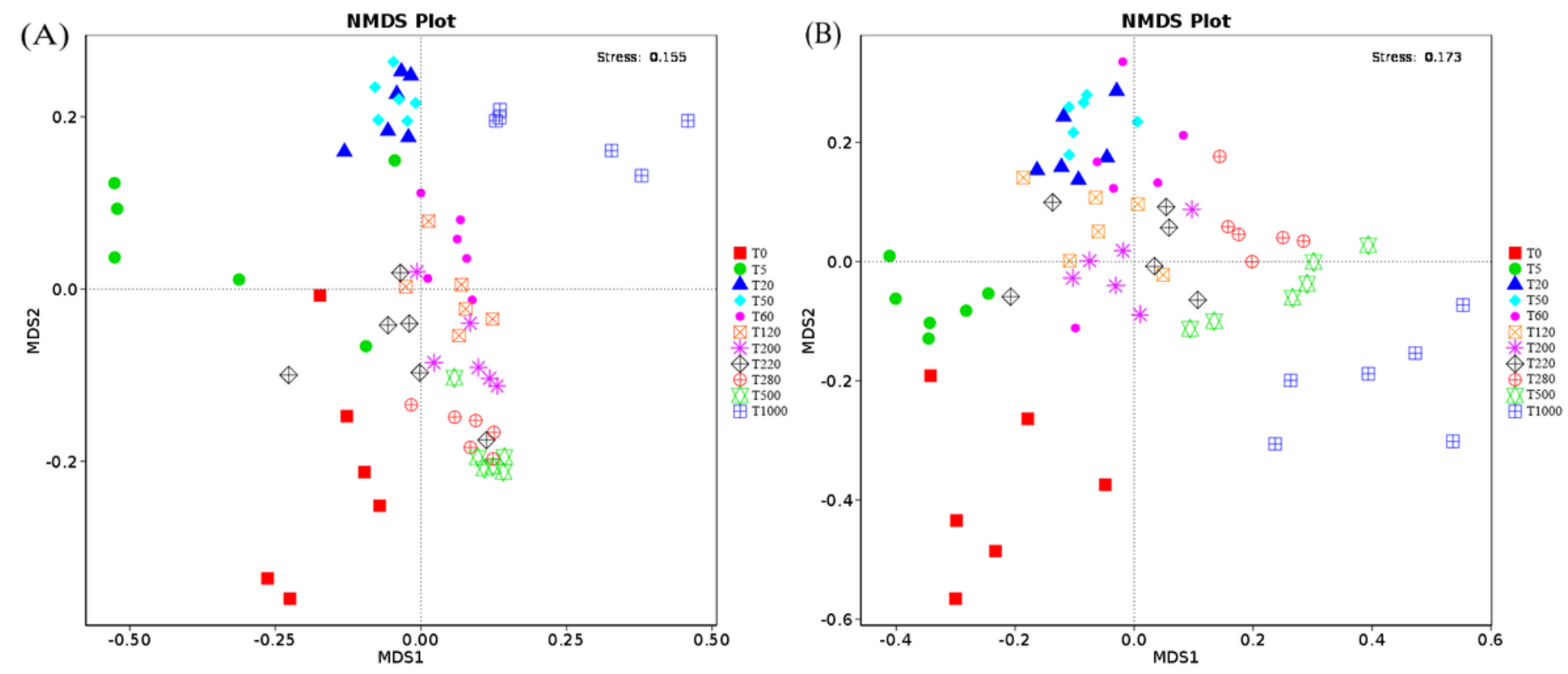

Figure 3

Bray-Curtis distance-based non-metric multi-dimensional scaling plot at the OTU level in reclaimed soils. (A) AOA community, (B) AOB community. 


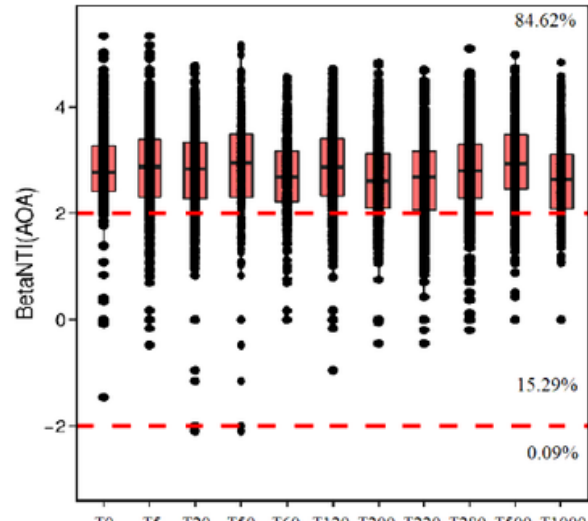

Reclamation Years

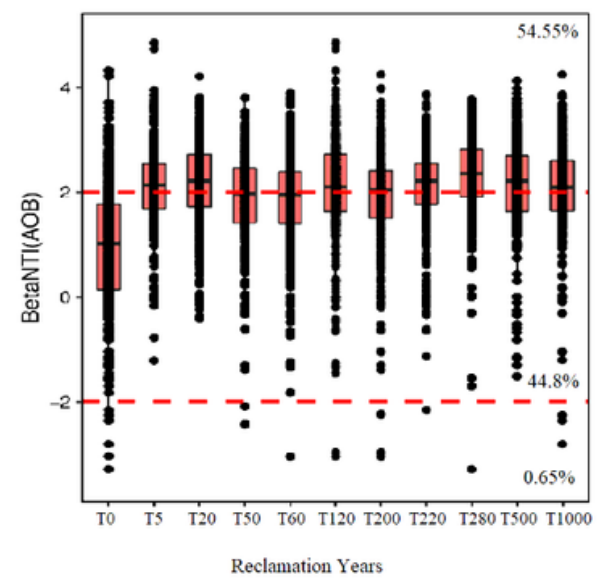

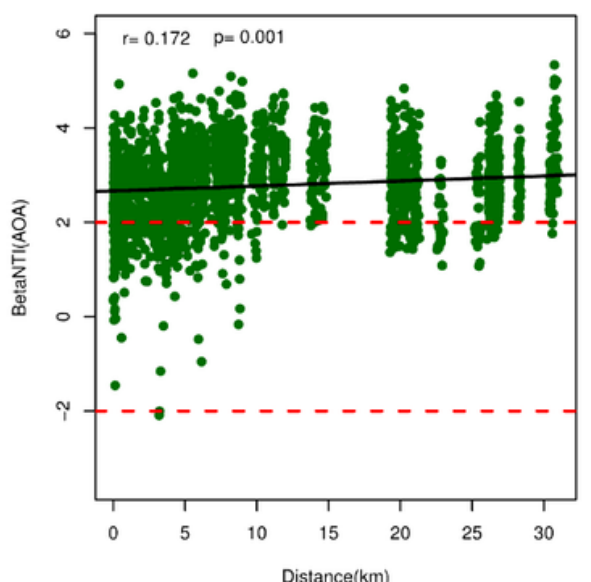
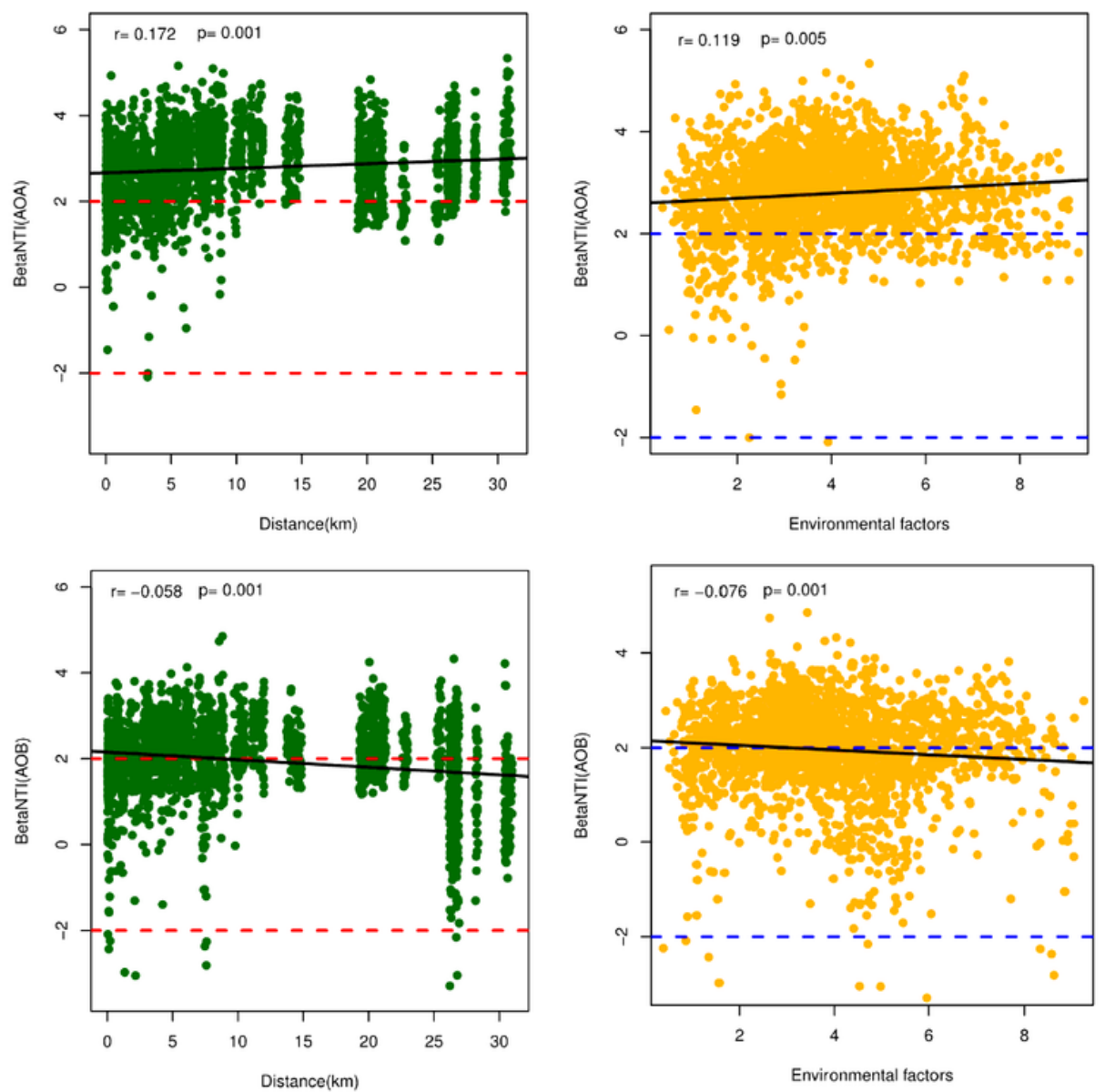

Figure 4

Boxplot of $\beta N T I$ values across reclamation years. Solid lines inside the box represent median values. Scatter plot distribution based on Mantel test. Spearman's correlation $r$ shows the relationship of $\beta N T I$ values of $A O A$ and $A O B$ communities with geographic distance and environmental variables (Euclidbased distance). 

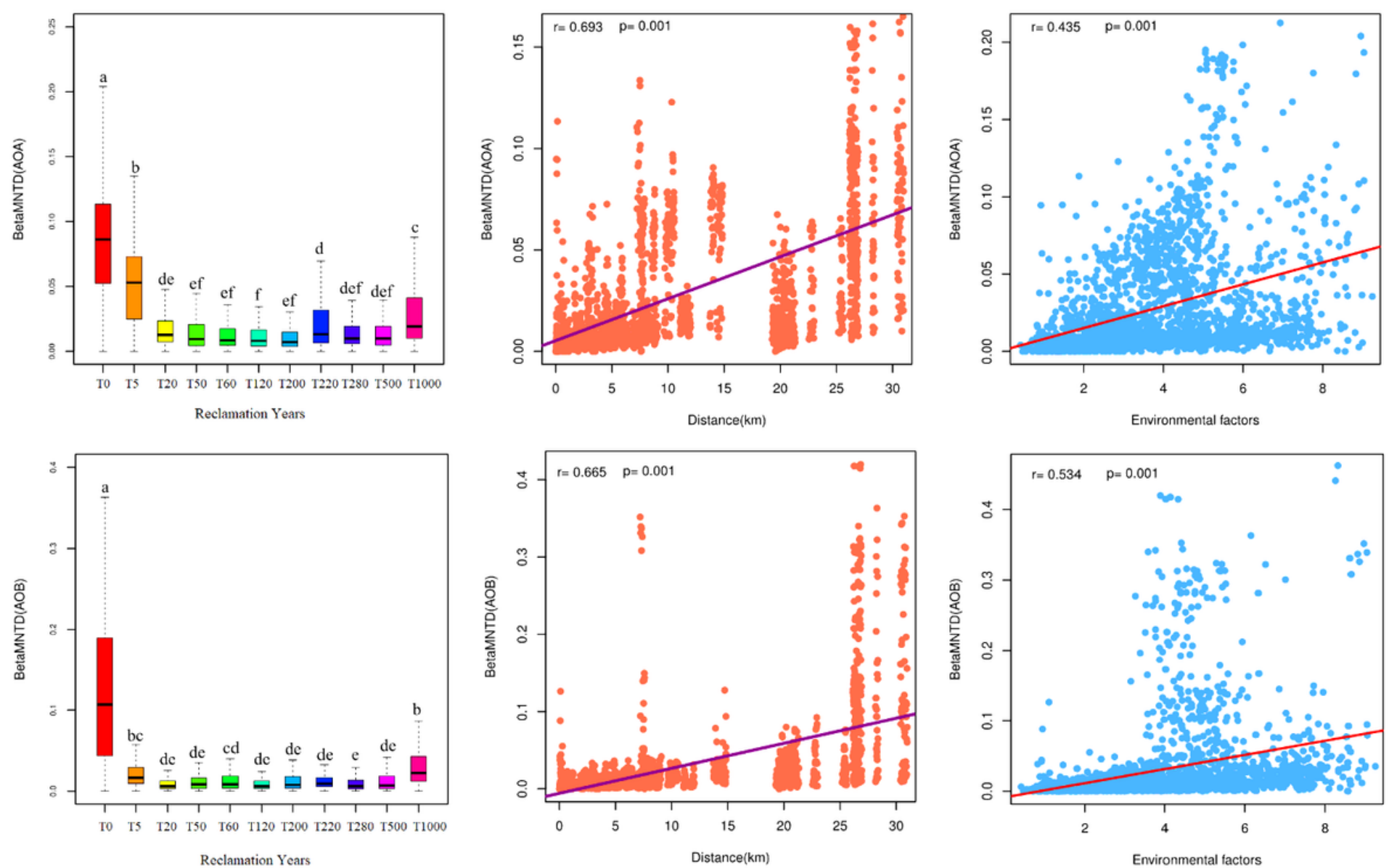

\section{Figure 5}

Boxplot indicating phylogenetic dissimilarity based on BMNTD at temporal scales. Different letters above boxes indicate significant differences (Duncan's test, $P<0.05$ ). Scatter plots indicate the correlation between $\beta M N T D$ values and spatial parameters (geographical distance and environmental parameters). Spearman correlation $(r)$ and probability values are provided. 
(A)

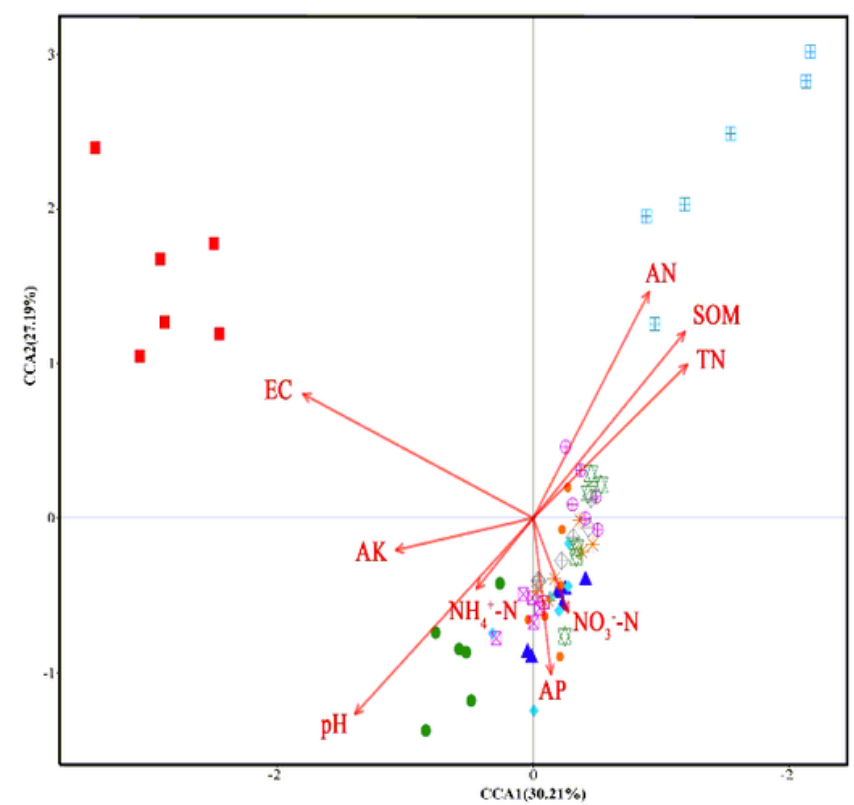

(C)

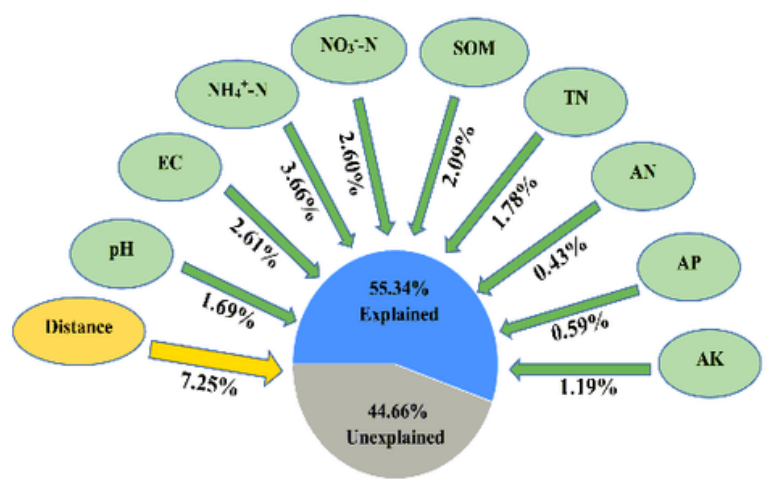

(B)

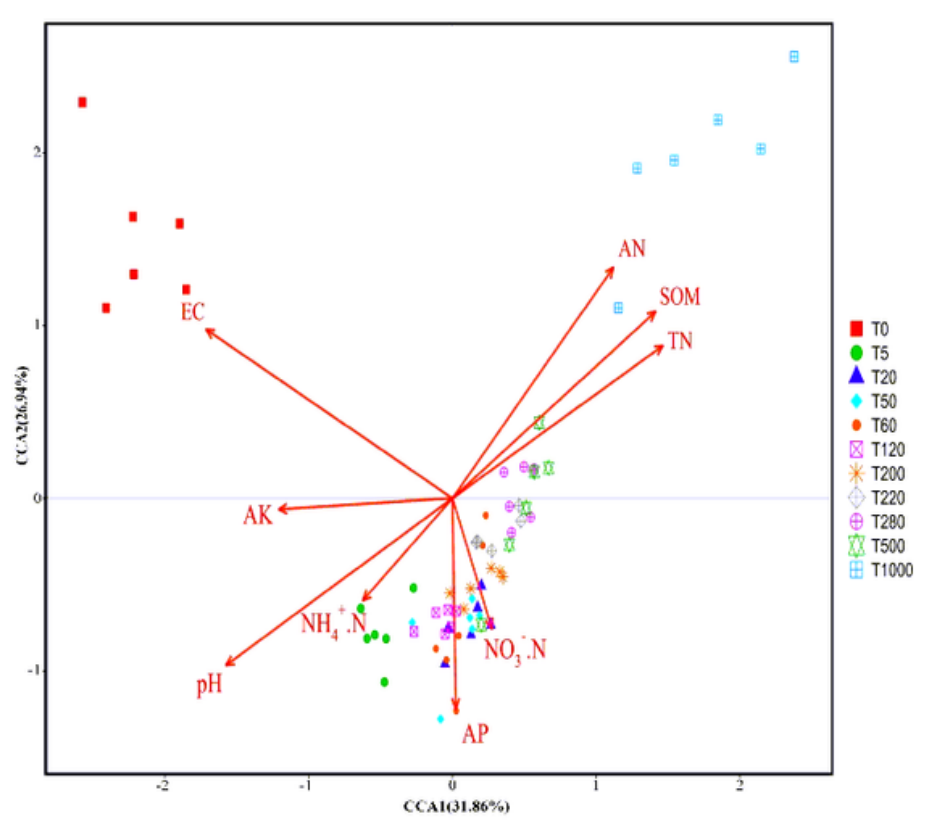

(D)

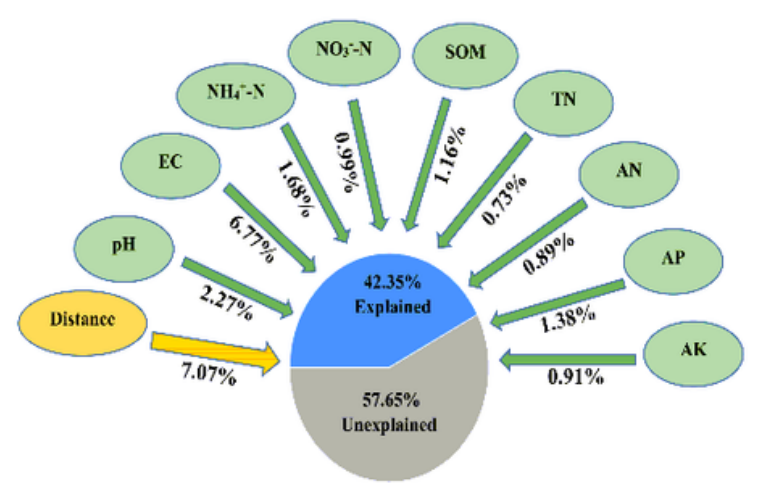

\section{Figure 6}

Relationship between environmental variables and microbial community structures. The length of the arrow represents the degree of correlation between environmental variables and community structures:

(A) archaeal community, (B) bacterial community. The quantitative contribution of environmental and spatial parameters based on variance partition analysis indicated the percentage of individual parameter variance on community structures of ammonia oxidizers: (C) archaeal community, (D) bacterial community.

\section{Supplementary Files}

This is a list of supplementary files associated with this preprint. Click to download.

- SupportingInformation.docx 